\title{
Prizes versus Contracts as Incentives for Innovation*
}

\author{
Yeon-Koo Che, ${ }^{\dagger} \quad$ Elisabetta Iossa, ${ }^{\ddagger} \quad$ Patrick ReY ${ }^{\S}$
}

November 25, 2020

\begin{abstract}
Procuring an innovation involves motivating a research effort to generate a new idea and then implementing that idea efficiently. If research efforts are unverifiable and implementation costs are private information, a trade-off arises between the two objectives. The optimal mechanism resolves the trade-off via two instruments: a cash prize and a follow-on contract. It primarily uses the latter, by favoring the innovator at the implementation stage when the value of the innovation is above a certain threshold and handicapping the innovator when the value of the innovation is below that threshold. A cash prize is employed as a supplementary incentive only when the value of innovation is sufficiently high. These features are consistent with current practices in the procurement of innovation and the management of unsolicited proposals.
\end{abstract}

JEL Classification: D44, H57, D82, O31, O38, O39.

Keywords: Contract rights, Innovation, Prizes, Procurement and R\&D.

${ }^{*}$ We would like to thank Vivek Bhattacharya, Roberto Burguet, Estelle Cantillon, Pierre-André Chiappori, Daniel Danau, Francesco Decarolis, Drew Fudenberg, Dan Garrett, Bruno Jullien, Laurent Lamy, Patrick Legros, Oliver Hart, David Martimort, Emilio Raiteri, Sara Shahanaghi, Giancarlo Spagnolo, Yossi Spiegel, Jean Tirole and participants at the 1st APIOC conference (Melbourne), the 1st BECCLE conference (Bergen), the 13th CRESSE conference (Heraklion), the 17th CRETE conference (Tinos), the 41st EARIE conference (Milan), the 7th TOI workshop (Zapallar), and seminars in Barcelona, Frankfurt, Lisbon, Mannheim, Nanchang, Naples, Paris, Siena, Tilburg, Tokyo, and at Bocconi, Columbia, Harvard, for their useful comments. We also thank Vincenzo Mollisi for his assistance with data collection. We gratefully acknowledge financial support from the European Research Council (ERC) under the European Community's Seventh Framework Programme (FP7/2007-2013) Grant Agreement $N^{\circ} 340903$, the Agence Nationale de la Recherche under the "Investing for the Future program" (grant ANR-17-EURE-0010), and the Italian Ministry of Education, PRIN 2017, Grant n. 2017Y5PJ43_001.

${ }^{\dagger}$ Department of Economics, Columbia University, yeonkooche@gmail.com.

${ }^{\ddagger}$ Department of Economics and Finance, University of Rome Tor Vergata, and GREEN-Bocconi, elisabetta.iossa@uniroma2.it.

${ }^{\S}$ Toulouse School of Economics, University of Toulouse Capitole, Toulouse, France, patrick.rey@tse-fr.eu. 


\section{Introduction}

Public procurement comprises a significant part of economic activity. ${ }^{1}$ An important aspect of public procurement is the role it plays in facilitating and stimulating innovation. Even though markets may fail to provide innovations, say due to the lack of appropriability, a government can bring them about by simply purchasing new technologies that fulfill desired social needs. Indeed, post-war history is rich with examples in which public procurement helped usher in new technologies - supercomputers, large passenger jets, semi-conductors and the internet, to name just a few. ${ }^{2}$ Technology-intensive public procurement also contributed to a wave of innovations in the late 70s and 80s (Cozzi and Impullitti, 2010), stimulated private R\&D spending in the early 2000s (Slavtchev and Wiederhold, 2016) and has significantly shaped the scientific problems with which inventors engage (Clemens and Rogers, 2020).

Against this backdrop, governments in many OECD countries have developed policies to utilize public procurement both as an innovation policy and as a strategy to boost the productivity of public spending in health, security, transport, energy and environment (OECD, 2017). ${ }^{3}$ Despite this growing public interest, however, it is not well understood how one should structure a procurement policy to serve this innovation goal. Different countries have adopted different approaches in rewarding and contracting innovations, without a clear consensus or understanding about them. Our goal is to provide such an understanding.

Procuring innovation presents a special challenge; unlike standard goods or services, the value of innovation is not realized until it is properly embodied and implemented into a tangible product or service. For a procurement to be successful, therefore, innovators must be incentivized ex ante to perform innovations, but ex post after innovation, one must decide efficiently whether an innovation project should be implemented and if so by whom. Although the promise of a follow-on contract can motivate innovation, the innovator may not be best suited for performing that contract. Common wisdom suggests that the followon contract should not be used as a tool for incentivizing innovation, for a cash prize can do that job without distorting allocation. Indeed, cash prizes have been used for procuring innovations - examples include the well-known Longitude Prize 1714, the recent EU Horizon Prizes Program, and the DARPA Robotics Challenges. Yet, there are also many instances in which follow-on contracts have been used as rewards for innovations, as in the Innovation

\footnotetext{
${ }^{1}$ According to OECD (2019), public procurement accounts for 12 percent of GDP in OECD countries. In the US, between 2006 and 2012 the government spent approximately $\$ 382$ billions in R\&D procurement, an average of $\$ 54.57$ billion per year (Decarolis et al., 2019). In Europe, Member States spent approximately 2.6 billion euros in 2011 for non-defense R\&D procurement (European Commission EC, 2014).

${ }^{2}$ See Cabral et al. (2006) and Geroski (1990) for instance.

${ }^{3}$ In Europe, a number of initiatives have been established to promote it (Edler and Georghiou, 2007) and new legislative provisions have been introduced to facilitate its use (Recitals 47-49 Directive 2014/24/EU and Recitals 57-59 Directive 2014/25/EU).
} 
Partnership and Unsolicited Proposal mechanisms reviewed below. We investigate how these two instruments, cash prizes and contract rights, should be combined to optimally fulfill the dual goals of innovation procurement.

To this end, we develop a model that captures the salient features of innovation procurement, namely the ex ante innovation decision and the ex post implementation decision. In our model, innovators first undertake costly efforts to innovate; then the buyer observes the resulting innovations, chooses one, and selects a supplier to implement it. Innovators' efforts stochastically increase the value of their innovations, but are unverifiable. Together with limited liability, this gives rise to a non-trivial moral hazard problem. Multiple suppliers, including the innovator, can implement the innovation but their costs are private information, which gives rise to an adverse selection problem. The value of an innovation is verifiable, which is realistic in many procurement settings, as we motivate later. This allows the buyer to grant cash prizes and to allocate the follow-on contract based on the value of innovation.

We first consider the case of a single innovator. This baseline model makes our analysis transparent and is also often relevant, as many innovative projects procured by public buyers are unsolicited and arrive one at a time. We first find that the common wisdom is indeed valid in the absence of adverse selection - when the cost of implementing the innovation is observed by the buyer. The optimal mechanism then relies solely on a cash prize and does not distort the assignment of the follow-on contract. Specifically, the buyer awards a prize to the innovator whenever the value of the innovation meets a threshold, and assigns the implementation to whichever supplier has the lowest cost.

The result is quite different, however, when there is adverse selection-i.e., suppliers have private information about the cost of implementing innovation. In this case, the information rents attached to the follow-on contract affect innovation incentives: the rents attached to highly innovative projects incentivize R\&D efforts, whereas those attached to poorly innovative projects disincentivize these efforts. As a small departure from the optimal secondbest auction generates only a second-order loss for the buyer at the implementation stage but a first-order improvement in incentives at the R\&D stage, it is always optimal to bias the assignment of the follow-on contract in favor of the innovator when its proposal is highly innovative, and against the innovator otherwise.

The same logic - namely, small distortions in the allocation of the follow-on contract generate only a second-order loss - also suggests that contract rights are preferred to cash prizes as incentives for innovation. Contract rights are used as long as the shadow value of motivating innovation is positive; but cash prizes are never used unless that shadow value exceeds the cost of public funds. Even in the latter case, the contract rights are "fully" exhausted (in a sense to be made clear) before cash prizes are offered as incentives. Thus, in striking contrast to common wisdom, contract rights serve as a primary incentive tool, whereas a cash prize only serves as a supplementary tool. 
We next show that these insights carry over when there are multiple innovators, a relevant scenario for R\&D contests and solicited procurement of innovations. First, contract rights still serve as a central tool for rewarding innovations: when assigning the follow-on contract, it is optimal to favor innovators who have high-value proposals, and disfavor those who have low-value proposals. Second, cash prizes still serve as a supplementary tool used only when an innovation is particularly valuable and/or when a research effort is particularly worth incentivizing. An interesting novel finding is a "winner-takes-all" principle: whenever a cash prize is used, it is never split among multiple innovators. When the value of innovation is particularly high, the optimal mechanism can be also implemented via delegation to a chosen innovator; that is, the innovator receives a fixed price equal to the value of the project and chooses whether to deliver the project itself or subcontract it to a different firm.

Our analysis also extends to the situation in which the value of innovation (not just the efforts) is non-contractible. In that case, the buyer is unable to condition the allocation of contract rights on the realized value of innovation. Nevertheless, the buyer finds it optimal to commit to an allocation rule that favors the innovator whenever the innovation project is implemented. As before, contract rights are used as a primary incentive; cash prizes are offered only if the demand for innovations is sufficiently strong and only after exhausting the contract rights as an incentive. Unlike the contractible innovation case, however, the buyer never handicaps the innovator.

Our analysis sheds light on several policy issues. First, and contrary to common wisdom, our theory provides a clear rationale for using contract rights as incentives for innovation. Interestingly, both the EU and the US have recently opened up to such use of contract rights. The US Congress has expanded the Department of Defense's authority to transition from a prototype project to a production contract without a competitive procedure. ${ }^{4}$ Likewise, the European Parliament has made it possible under the Innovation Partnership procedure to award the follow-on contract to the supplier of a selected innovation.

Second, our analysis cautions against bundling research and development. The degree to which the innovator is favored in the assignment of follow-on contracts should depend instead on the value of its innovation. In practice, this can be achieved by giving the innovator a bidding credit in the form of additional score points in the follow-on tender. Such a biddingcredit system is used in Chile and South Korea to encourage the submission of unsolicited but innovative proposals. In South Korea, there is also evidence that the authorities adjust the bonus points based on the project value. Other countries such as Italy also treat proposers of unsolicited projects favorably in follow-on contract tenders. Interestingly, our analysis shows that favoring proponents of innovative projects is particularly desirable for innovations creating new technologies that are not easy to contract on, a likely scenario for unsolicited

\footnotetext{
${ }^{4}$ Section 815 of the National Defense Authorization Act for Fiscal Year 2016, available at: https://www.congress.gov/bill/114th-congress/house-bill/1735.
} 
proposals.

Bid-preference systems are often used as an affirmative action (see e.g., the Small Business Preference Program in the US) or as a strategy to reduce the procurement costs when competitors are asymmetric. Our paper emphasizes instead the incentive benefit of these systems and recommends them as part of a broader strategy to promote innovation via public procurement, building upon the best practice for unsolicited proposals. A recent laboratory experiment studying the effect of this recommendation confirms the positive impact of the scheme (Camboni et al., 2019).

The paper is organized as follows. Section 2 introduces a baseline model with a single innovator and develops the main analysis. In Section 3, we extend the analysis to the case of multiple innovators. In Section 4, we show how our insights carry over when projects offering different values also involve different cost distributions, when handicaps are ruled out, and when the value of the innovation is not verifiable. In Section 5, we discuss the implications for unsolicited proposal and innovation procurement policies. In Section 6, we discuss the related literature. In Section 7, we provide some concluding remarks.

\section{Procurement with a Single Innovator}

We consider here the case in which a single innovator may propose a project. This case serves to explain the main results in a simple way, but it is also descriptive of unsolicited innovations, which involve single innovation projects.

\section{$2.1 \quad$ Model}

A buyer (e.g., a public agency) wishes to procure an innovative project in two stages: innovation and implementation. In the first stage, an innovator, say firm 1 , exerts effort $e \geq 0$ to create a project. The effort $e$ costs the innovator $c(e) \geq 0$ but stochastically increases the value $v$ of the project. We assume that $c(\cdot)$ is increasing, strictly convex, twice differentiable and such that $c(0)=c^{\prime}(0)=0$. The value $v$ is drawn from $V:=[\underline{v}, \bar{v}]$ according to a cumulative distribution function (cdf), $F(\cdot \mid e)$, which admits a twice-differentiable density $f(\cdot \mid e)$ in the interior. An increase in $e$ shifts the distribution $F(\cdot \mid e)$ in the sense of the monotone likelihood ratio property:

$$
\frac{f\left(v^{\prime} \mid e^{\prime}\right)}{f\left(v \mid e^{\prime}\right)}>\frac{f\left(v^{\prime} \mid e\right)}{f(v \mid e)}, \text { for any } v^{\prime}>v \text { and } e^{\prime}>e .
$$

This implies $F_{e}(v \mid e)<0$ for all $v \in(\underline{v}, \bar{v})$ and $e \geq 0$. We further assume that innovation efforts have diminishing marginal returns: $F_{e e}(\cdot \mid \cdot) \geq 0$. [The latter is used only in Section 
4.1.]

The innovator's effort $e$ is unobservable. The value $v$ is instead publicly observable and verifiable. This is a reasonable assumption in most procurement contexts, as projects can often be described using precise functional and performance terms. For example, in the tenders of faster medical tests, greener transport units, or interoperable information and communication technology (ICT) systems, $v$ may correspond to the speed of the medical test, the fuel-efficiency of the transport unit, or the technical functionalities of the ICT system featured by prototypes, respectively. ${ }^{5}$ Later, however, we explore the case in which the project value $v$ is not contractible and discuss how our insights can be transposed to such situations (see Section 4.3).

In the second stage, $n$ potential firms, including the innovator, compete to implement the project. Each firm $i \in N:=\{1, \ldots, n\}$ faces a cost $\theta_{i}$, which is drawn from $\Theta:=[\underline{\theta}, \bar{\theta}]$ according to a cdf $G_{i}(\cdot)$, which admits density $g_{i}(\cdot)$ in the interior. We assume that $\underline{\theta}<\bar{v}$ and that, for each $i \in N, G_{i}\left(\theta_{i}\right) / g_{i}\left(\theta_{i}\right)$ is nondecreasing in $\theta_{i}$ and $\lim _{\theta_{i \downarrow} \underline{\theta}} G_{i}\left(\theta_{i}\right) / g_{i}\left(\theta_{i}\right)=0$. The $\operatorname{cost} \theta_{i}$ is privately observed by the firm. ${ }^{6}$

All parties are risk-neutral and the primitive, $\left(F,\left\{G_{i}\right\}, c\right)$, is common knowledge among all players. If the buyer procures the project of value $v$ from firm $i \in N$ and in the process pays $\left(t_{1}, \ldots, t_{n}\right)$ to the firms, then she enjoys the payoff of $v-\sum_{i \in N} t_{i}$, firm $i$ enjoys the payoff of $t_{i}-\theta_{i}$, and any firm $j \neq i$ enjoys the payoff of $t_{j}$. All parties obtain zero payoff if the project is not implemented, except for the innovation effort sunk by firm 1 .

By the revelation principle, we can formulate the problem facing the buyer as that of choosing a direct revelation mechanism - namely, a direct mechanism that is incentivecompatible. A direct mechanism is a mapping $(x, t): V \times \Theta^{n} \rightarrow \Delta^{n} \times \mathbb{R}^{n}$ that specifies for each $i$ the probability $x_{i}(v, \theta)$ that firm $i$ implements the project and the payment $t_{i}(v, \theta)$ it receives, when the project proposed by firm 1 has value $v$ and firms report types $\theta:=\left(\theta_{1}, \ldots, \theta_{n}\right)$. By construction, the assignment probabilities must lie in $\Delta^{n}:=\left\{\left(x_{1}, \ldots, x_{n}\right) \in[0,1]^{n} \mid \sum_{i \in N} x_{i} \in[0,1]\right\}$. The dependence of the mechanism on the project value $v$ reflects its verifiability, whereas the absence of the argument $e$ reflects its unobservability to the buyer.

The timing of the game is as follows:

1. The buyer offers a direct revelation mechanism $(x, t)$.

2. The innovator chooses its effort $e$, and the value $v$ is realized.

\footnotetext{
${ }^{5}$ In practice, several mechanisms use R\&D expenses, which can be interpreted as a proxy for the expected value of the innovation; see the discussion at the end of Section 2.4.

${ }^{6}$ The parameter $\theta_{i}$ should be interpreted as a cost estimate at the time of contracting, since the cost of implementing an innovation remains often uncertain even after its characteristics are revealed.
} 
3. Firms observe $v$ and their respective costs, and decide whether to participate.

4. Participating firms report their costs; the project is implemented (or not) and transfers are made according to the mechanism.

For each $v \in V$, let

$$
u_{i}\left(v, \theta_{i}^{\prime} \mid \theta_{i}\right):=\mathbb{E}_{\theta_{-i}}\left[t_{i}\left(v,\left(\theta_{i}^{\prime}, \theta_{-i}\right)\right)-\theta_{i} x_{i}\left(v,\left(\theta_{i}^{\prime}, \theta_{-i}\right)\right)\right]
$$

denote the interim expected profit that firm $i$ will obtain by reporting a cost $\theta_{i}^{\prime}$ when its true cost is $\theta_{i}$, and let

$$
U_{i}\left(v, \theta_{i}\right):=u_{i}\left(v, \theta_{i} \mid \theta_{i}\right)
$$

denote firm $i$ 's expected payoff under truthful revelation of its $\operatorname{cost} \theta_{i}$. The revelation principle ensures that there is no loss in restricting attention to a direct mechanism $(x, t)$ that satisfies incentive compatibility:

$$
U_{i}\left(v, \theta_{i}\right)=\max _{\tilde{\theta}_{i}} u_{i}\left(v, \tilde{\theta}_{i} \mid \theta_{i}\right), \quad \forall i \in N, \forall v \in V, \forall \theta_{i} \in \Theta
$$

Note that we require incentive compatibility in the interim sense; we shall later show that the optimal mechanism can be in fact implemented in dominant strategies.

All players have limited ability to sustain a loss. We assume that they cannot end up with negative payoffs (in expectation) given their information at the time of contracting. In particular, as firms can freely decide whether to participate once $v$ is realized and they have learnt their cost, the mechanism $(x, t)$ must satisfy individual rationality:

$$
U_{i}\left(v, \theta_{i}\right) \geq 0, \quad \forall i \in N, \forall v \in V, \forall \theta_{i} \in \Theta
$$

As we shall see, together with $(I C)$, this requirement compels the buyer to leave information rents to the selected supplier. It also ensures that the innovator obtains a non-negative expected payoff. ${ }^{7}$ This assumption is natural in many settings. For example, in the case of unsolicited proposals, the identities of the innovator and firms capable of executing the project are unknown until the nature of the project - its value and the costs of implementing it - is determined. This makes it difficult for the buyer to approach prospective suppliers for early buy-in. ${ }^{8}$ Further, buyers are reluctant to force firms into potentially loss-making contracts as this would cause severe service disruptions in case of default.

\footnotetext{
${ }^{7}$ As $c(0)=0$, the innovator can secure a zero payoff by exerting no effort and then not participating in the mechanism.

${ }^{8}$ If the buyer could instead require firms to "buy-in" via an upfront fee, it could use this fee to extract all future rents and achieve the first-best outcome at the implementation stage; as shown by Proposition 1, there would then be no gain from using contract rights to reward the innovator: cash prizes would be preferable.
} 
We also assume that the buyer faces her own limited liability; she must at least break even for each realized value $v$ of the project. That is, the mechanism $(x, t)$ must satisfy:

$$
\mathbb{E}_{\theta}[w(v, \theta)] \geq 0, \quad \forall v \in V
$$

where

$$
w(v, \theta):=\sum_{i \in N}\left[x_{i}(v, \theta) v-t_{i}(v, \theta)\right]
$$

denotes the buyer's surplus from implementing a project of value $v$. Such limited liability may arise from political constraints. Public projects are scrutinized by stakeholders such as legislative bodies, project evaluation authorities, consumer advocacy groups, and the media, who might reject projects that are likely to incur a net loss. The particular form of the constraint $(L L)$ is not crucial, however; the general thrust of our analysis carries through, as long as there is some cap on either the maximum loss that the buyer can sustain or the maximum payment that she can make to the firms. ${ }^{9}$ Indeed, public agencies and local authorities typically operate within well-defined budget limits.

Finally, as the innovator chooses effort $e$ in his best interest, the mechanism must also satisfy the following moral hazard condition:

$$
e \in \arg \max _{\tilde{e}} \mathbb{E}_{v, \theta}\left[U_{1}\left(v, \theta_{1}\right) \mid \tilde{e}\right]-c(\tilde{e})
$$

The buyer's problem is to choose an optimal mechanism satisfying these constraints. More formally, she solves the problem:

$$
\max _{x, t, e} \mathbb{E}_{v, \theta}[w(v, \theta) \mid e]
$$

subject to

$$
(I R),(I C),(L L) \text { and }(M H) \text {. }
$$

\subsection{Benchmarks}

Before solving $[P]$, we begin with two benchmarks. By turning off the two main features of our model - ex post adverse selection and ex ante moral hazard - one at a time, these benchmarks will help inform us of their respective roles in our main characterization.

\footnotetext{
${ }^{9}$ Without such a constraint, the buyer could incentivize innovation at (almost) no cost by paying an arbitrarily large bonus to the innovator for a vanishing small set of projects with values close to $\bar{v}$. Such a scheme achieves the first-best but is unreasonable and unrealistic. If $(L L)$ were replaced by a budget cap, then our characterization in Proposition 3 would change in a natural way, as described in footnote 13.
} 
No adverse selection ex post. In this benchmark, the buyer observes the firms' implementation costs so that there is no adverse selection problem: once the buyer approves the project, she can implement it without leaving any informational rent to the firms. Formally, the buyer's problem is the same as $[P]$, except that the constraint $(I C)$ is now absent. We label such a relaxed problem $[P-F B]$, where "FB" refers to the first-best outcome.

We show that distorting the selection of the supplier with contract rights is never desirable in this case. In line with conventional wisdom, cash prizes are the best instrument for the provision of innovation incentives:

Proposition 1 (First-Best). There exist $\lambda^{F B}>0$ and $e^{F B}>0$ such that the optimal mechanism solving $[P-F B]$ selects firm $i \in N$ to implement the project with probability

$$
x_{i}^{F B}(v, \theta):=\left\{\begin{array}{cc}
1 & \text { if } \theta_{i}<\min \left\{v, \min _{j \neq i} \theta_{j}\right\} \\
0 & \text { otherwise }
\end{array}\right.
$$

and a transfer that simply compensates the winning firm's cost, except that firm 1 is additionally paid a cash prize equal to

$$
\rho^{F B}(v):=\left\{\begin{array}{cl}
\mathbb{E}_{\theta}\left[\sum_{i \in N} x_{i}^{F B}(v, \theta)\left(v-\theta_{i}\right)\right]>0 & \text { if } v>\hat{v}^{F B}, \\
0 & \text { if } v<\hat{v}^{F B}
\end{array}\right.
$$

where $\hat{v}^{F B}$ is the unique $v \in(\underline{v}, \bar{v})$ that solves

$$
\beta^{F B}(v):=\lambda^{F B} \frac{f_{e}\left(v \mid e^{F B}\right)}{f\left(v \mid e^{F B}\right)}=1 .
$$

Proof. See Appendix A.

Rewarding the innovator with contract rights distorts allocation, whereas doing so with a cash prize does not. Consequently, the first-best mechanism assigns the follow-on contract efficiently to the firm with the lowest cost, provided that this cost is lower than the value $v$ of the project. Innovation incentives are provided solely by a cash prize. As the realized project value $v$ is an informative signal about the innovator's effort, incentives are provided by rewarding the innovator when its project is valuable, and punishing it otherwise. Specifically, the optimal mechanism awards a cash prize to the innovator when the opportunity cost of public funds - normalized here to 1 - is less than the incentive benefit $\beta^{F B}(v)=\lambda^{F B} \frac{f_{e}\left(v \mid e^{F B}\right)}{f\left(v \mid e^{F B}\right)}$. The incentive benefit consists of two terms: the shadow value $\lambda^{F B}$ of relaxing the incentive constraint $(M H)$ and the informativeness measure $\frac{f_{e}\left(v \mid e^{F B}\right)}{f\left(v \mid e^{F B}\right)}$ of $v$ as a signal for effort $e .{ }^{10}$ The shadow value is strictly positive since $(M H)$ binds at the optimum. Meanwhile, $(M L R P)$

\footnotetext{
${ }^{10}$ This measure of informativeness plays a prominent role in the classical moral hazard model. See Hölmstrom (1979).
} 
implies that the informativeness measure is increasing in $v$, reflecting the fact that high $v$ is an indication of a high $e$. It follows that there exists a threshold $\hat{v}^{F B}$ such that a cash prize is awarded if and only if $v$ is above that threshold. ${ }^{11}$

Individual rationality $(I R)$ for firms limits the punishment they can sustain (as they cannot suffer loss) whereas limited liability $(L L)$ limits the rewards given to them (as the buyer cannot pay more than the full value of the project). As a result, the innovator's incentive payment has a bang-bang structure: the innovator obtains no prize when $v$ falls short of a given threshold, and the prize equals the entire surplus when $v$ exceeds that threshold.

No moral hazard ex ante. Suppose next that there is no moral hazard problem; i.e., the project value follows some exogenous distribution $F(v)$. Then, the problem facing the buyer is the same as $[P]$, except that the constraint $(M H)$ is absent and the distribution function $F(v \mid e)$ is replaced by the exogenous distribution $F(v)$. The resulting problem, labeled $[P-S B]$, conforms to the standard optimal auction design problem, except for the $(L L)$ constraint. Ignoring the latter, the optimal auction is the standard "second-best mechanism" familiar from Myerson (1981). One can easily see that this mechanism satisfies $(L L)$ and thus constitutes a solution to $[P-S B]$ as well. As the analysis is standard, we provide the characterization of the solution without a proof.

Proposition 2 (Second-best). The optimal mechanism solving $[P-S B]$ is the standard second-best mechanism, which selects firm $i \in N$ to implement the project with probability

$$
x_{i}^{S B}\left(v, \theta_{i}\right):=\left\{\begin{array}{cc}
1 & \text { if } J_{i}\left(\theta_{i}\right) \leq \min \left\{v, \min _{j \neq i} J_{j}\left(\theta_{j}\right)\right\} \\
0 & \text { otherwise }
\end{array}\right.
$$

where $J_{i}\left(\theta_{i}\right):=\theta_{i}+\frac{G_{i}\left(\theta_{i}\right)}{g_{i}\left(\theta_{i}\right)}$ is firm i's virtual cost.

\subsection{Optimal mechanism}

We now consider problem $[P]$, in which the buyer faces ex post adverse selection with respect to firms' implementation costs as well as ex ante moral hazard with respect to the innovator's effort. Throughout, we assume the existence of an optimal mechanism that induces an interior effort level $e^{*}$. The following Proposition characterizes this optimal mechanism:

Proposition 3. There exists $\lambda^{*}>0$ such that the optimal mechanism solving $[P]$ :

\footnotetext{
${ }^{11}$ The threshold must be interior. If it were zero, then the buyer would receive no surplus. If it were one, then the innovator would make no effort, which is never optimal given the assumption that $c^{\prime}(0)=0$.
} 
(i) selects firm $i \in N$ to implement the project (i.e., $x_{i}^{*}(v, \theta)=1$ ) if

$$
K_{i}^{*}\left(v, \theta_{i}\right) \leq \min \left\{v, \min _{j \neq i} K_{j}^{*}\left(v, \theta_{j}\right)\right\},
$$

where $K_{i}^{*}\left(v, \theta_{i}\right):=\theta_{i}$ if $i \neq 1$ and

$$
K_{1}^{*}\left(v, \theta_{1}\right):=J_{1}\left(\theta_{1}\right)-\min \left\{\beta^{*}(v), 1\right\} \frac{G_{1}\left(\theta_{1}\right)}{g_{1}\left(\theta_{1}\right)} \text {, with } \beta^{*}(v):=\lambda^{*} \frac{f_{e}\left(v \mid e^{*}\right)}{f\left(v \mid e^{*}\right)} .
$$

(ii) pays firm $i \in N$ a transfer $t_{i}^{*}(v, \theta)=\rho_{i}^{*}(v)+\hat{\theta}_{i}\left(v, \theta_{-i}\right) x_{i}^{*}(v, \theta)$, where

$$
\hat{\theta}_{i}\left(v, \theta_{-i}\right):=\sup \left\{\theta_{i} \in \Theta \mid x_{i}^{*}\left(v, \theta_{i}, \theta_{-i}\right)=1\right\}
$$

and $\rho_{i}^{*}(v):=0$ except for $i=1$ if $\beta^{*}(v)>1$, in which case

$$
\rho_{1}^{*}(v):=\mathbb{E}_{\theta}\left[\sum_{i \in N} x_{i}^{*}(v, \theta)\left\{v-\hat{\theta}_{i}\left(v, \theta_{-i}\right)\right\}\right] \geq 0,
$$

which is strictly positive whenever $n>1$ or $v>\bar{\theta} \cdot{ }^{12}$

This payment rule implements the allocation rule $x^{*}$ in dominant strategies: that is, it is a weakly dominant strategy for each firm $i$ to report its cost truthfully.

Proof. See Appendix B.

Proposition 3 suggests that the optimal mechanism distorts the contract allocation against the innovator for low value projects and in favor of the innovator for high value projects. As a complementary instrument, a cash prize, equal to the buyer's surplus, can be awarded for very high project values.

The intuition is as follows. First, $(M H)$ binds at the optimum - namely, $\lambda^{*}>0$. This reflects the fact that the incentives provided by the second-best mechanism described in Proposition 2 (which would obtain if $\lambda^{*}=0$ ) is not sufficient. To see this, suppose, starting from the second-best allocation, that the buyer slightly distorts the allocation in favor of the innovator when the value $v$ of the innovation is very high, and against it when $v$ is very low. This will generate only a second-order loss for the buyer at the implementation stage but a first-order improvement in incentives at the innovation stage, as it will increase the information rent for the innovator when $v$ is high and reduce it when $v$ is low. Consequently, the buyer wishes to incentivize innovation more than the second-best mechanism

\footnotetext{
${ }^{12}$ If $n=1$ and $v \leq \bar{\theta}$, then $\hat{\theta}_{1}(v)=v$, since $\beta^{*}(v)>1$ implies $K_{1}^{*}\left(v, \theta_{1}\right)=\theta_{1}$. Hence, in that case, the informational rent exhausts the net value of the project, so the cash prize is zero.
} 
does. Further, the fact that a small distortion generates only a second-order loss at the implementation stage suggests that the buyer will want to use contract rights to incentivize innovation. Consequently, $\lambda^{*}>0$ calls for the allocation and payment to depart from the second best mechanism.

The optimal degree of distortion from the second best is determined by the shadow value $\beta^{*}(v):=\lambda^{*} \frac{f_{e}\left(v \mid e^{*}\right)}{f\left(v \mid e^{*}\right)}$ of relaxing $(M H)$, which we call "incentive benefit." Specifically, each dollar of information rent paid to the innovator when the project is worth $v$ yields an incentive benefit $\beta^{*}(v)$, and this benefit should be credited in the "shadow cost" of allocating the follow-on contract. For each non-innovating firm $i \neq 1$, this shadow cost equals the virtual cost $J_{i}\left(\theta_{i}\right)$, just as in the second-best mechanism; but for the innovator, the shadow cost is reduced by the incentive benefit $\beta^{*}(v)$. Besides this modification, the allocation rule is the same as before: the firm with the lowest shadow cost wins the contract as long as it is less than $v$.

The sign and magnitude of the incentive benefit $\beta^{*}(v)$ informs the type of distortion prescribed by the optimal mechanism. From (MLRP), $\beta^{*}(v)$ is increasing in $v$, and there exists a cutoff $\tilde{v} \in(\underline{v}, \bar{v})$ such that $\beta^{*}(\tilde{v})<0$ if $v<\tilde{v}$ and $\beta^{*}(\tilde{v})>0$ if $v>\tilde{v}$. Intuitively, the information rent paid to the innovator acts as an incentive for innovation when the value is above $\tilde{v}$ - a signal of high effort-, so the optimal mechanism calls for distorting the allocation in favor of the innovator. By contrast, the information rent acts as a disincentive for innovation when the project has low value - a signal of low effort-, so the optimal mechanism calls for handicapping, or distorting the allocation away from, the innovator when $v<\tilde{v}$.

If $v>\tilde{v}$ but $v<\hat{v}:=\sup \left\{v \in V \mid \beta^{*}(v) \leq 1\right\}$, then each dollar paid to the innovator generates benefit $\beta^{*}(v) \in(0,1)$. This means that the allocation should be distorted to favor the innovator, as mentioned above, but since the benefit falls short of the opportunity cost of public funds, cash prizes should not be used in this case.

If $v>\hat{v}$, then $\beta^{*}(v)>1$. In this case, each dollar paid to the innovator generates more than a dollar benefit to the buyer, so the buyer wishes to maximize the payment to innovator. This means that $(L L)$ binds for such $v$. Intuitively, the buyer pledges the entire project surplus to the innovator when there is a strong enough signal of the innovator's effort. ${ }^{13}$ The question is how the innovator should be paid: contract payment or cash prize? The former is still utilized: the innovator receives "full" credit for the information rents it earns, so its shadow cost equals the true cost; i.e., $K_{1}\left(v, \theta_{1}\right)=\theta_{1}$, which significantly distorts the allocation in favor of the innovator. Any further distortion is inefficient, however, as it

\footnotetext{
${ }^{13}$ At first glance, this may appear paradoxical as the buyer enjoys no surplus when this happens. But the incentives created in this way bear fruits when $v<\hat{v}$, and are large enough to justify the maximal payment made when $v>\hat{v}$. If $(L L)$ were replaced by a maximum budget, a similar characterization applies; namely, for $v$ above some cutoff, a cash prize that exhausts the budget will be awarded to the innovator.
} 
simply shrinks the total surplus that can be paid to the innovator. Consequently, the buyer pays the remaining surplus to the innovator via a lump-sum cash prize, regardless of whether the innovator receives a follow-on contract. ${ }^{14}$

Strictly speaking, we could have $\hat{v}=\bar{v}$, in which case a cash prize is never employed in the optimal contract; all innovation incentives would then be provided exclusively through contract rights. One expects that cash prizes will be employed if the innovation is sufficiently valuable or if follow-on contracts do not generate sufficient rents because either the competition at the implementation stage is too fierce or there is not enough heterogeneity among firms in implementation costs. Online Appendix A makes this observation precise.

We state these implications more formally as follows.

Corollary 1. There exist $\tilde{v}$ and $\hat{v}$ satisfying $\underline{v}<\tilde{v}<\hat{v} \leq \bar{v}$ such that the optimal mechanism has the following characteristics:

- If $v<\tilde{v}$, then no cash prize is awarded, but the innovator is handicapped in the allocation of the follow-on contract: $x_{1}^{*}(v, \theta) \leq x_{1}^{S B}(v, \theta)$, whereas $x_{i}^{*}(v, \theta) \geq x_{i}^{S B}(v, \theta)$ for all $i \neq 1$;

- If $\tilde{v}<v<\hat{v}$, then no cash prize is awarded, but the allocation of the follow-on contract is biased in favor of the innovator: $x_{1}^{*}(v, \theta) \geq x_{1}^{S B}(v, \theta)$, whereas $x_{i}^{*}(v, \theta) \leq x_{i}^{S B}(v, \theta)$ for all $i \neq 1$;

- If $v>\hat{v}$ (which only occurs if $\hat{v}<\bar{v}$ ), then the innovator is awarded a cash prize and the follow-on contract is further biased in its favor: $x_{1}^{*}(v, \theta) \geq x_{1}^{F B}(v, \theta)\left(\geq x_{1}^{S B}(v, \theta)\right),{ }^{15}$ whereas $x_{i}^{*}(v, \theta) \leq x_{i}^{S B}(v, \theta)$ for all $i \neq 1$.

Figure 1 depicts the allocation rule for two firms $(n=2)$, under different values of innovation. The dotted lines correspond to the allocation boundaries under the secondbest mechanism (recall Proposition 2). The solid lines represent the boundaries under the optimal mechanism and highlight the nature of the distortion that it induces. As shown, the innovator receives the production contract with progressively higher probability as the value $v$ of the project increases.

In the last case, in which $v>\hat{v}$, the buyer pays the full expected surplus from the project, and the shadow cost of the innovator then reduces to its production cost, meaning that the innovator is treated as an "in-house" supplier. A simple delegation scheme can then implement the optimal mechanism.

\footnotetext{
${ }^{14}$ This is required to maintain incentives - including dominant strategy implementation. In particular, the innovator cannot simply be paid $v$ whenever it wins the contract, as this would affect the allocation. The fact that the cash prize is independent of contract assignment distinguishes it from a contract payment. ${ }^{15}$ If $n=1$, then $x_{1}^{*}(v, \theta)=x_{1}^{F B}(v, \theta)\left(\geq x_{1}^{S B}(v, \theta)\right)$.
} 


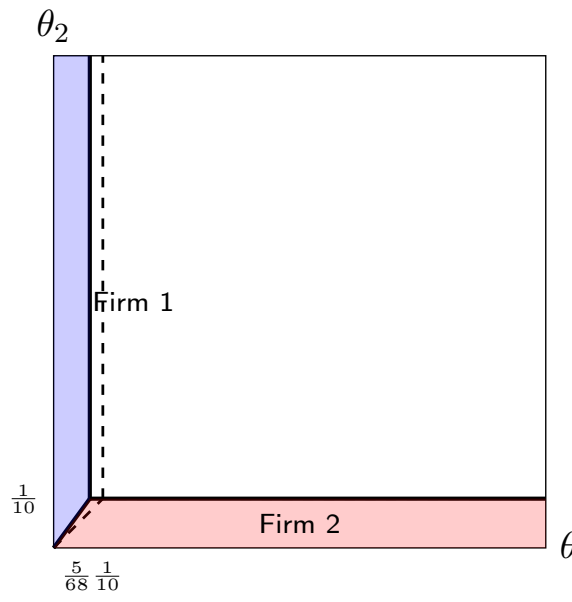

(a) $v<\tilde{v}$

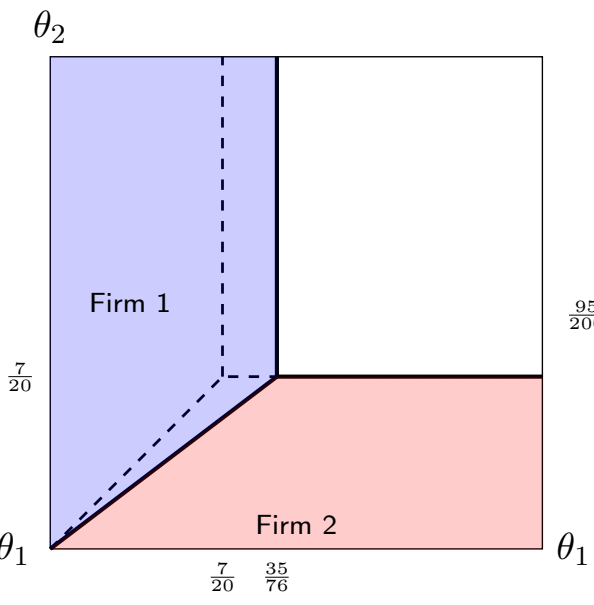

(b) $\tilde{v}<v<\hat{v}$

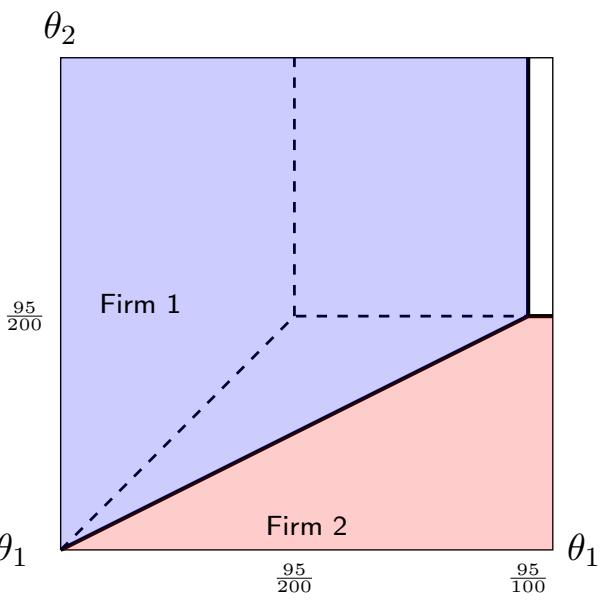

(c) $v>\hat{v}$

Note: $v$ is distributed from $[0,1]$ according to density $f(v \mid e)=e+2(1-e)(1-v), c(e)=0.066 e$ for $e \in[0,1]$, and the firms' implementation costs are uniformly distributed from $[0,1]$. Panel (a) assumes $v=1 / 5$, panel (b) assumes $v=7 / 10$ and panel (c) is for $v=95 / 100$. See the Online Appendix B for the derivation.

Figure 1 - Contract assignment under different values of $v$.

REMARK 1 (Implementation via delegation). Assume $v>\hat{v}$. Suppose the buyer simply offers a lump-sum payment of $v$, namely the entire project value, to the innovator for delivering the project by itself or by outsourcing it from a different firm $i \neq 1$. Facing this offer, the innovator will in turn propose an auction mechanism $(x(v, \cdot), t(v, \cdot)): \Theta^{n} \rightarrow \Delta \times \mathbb{R}^{n-1}$ so as to solve:

$$
\begin{gathered}
\max _{x, t} \mathbb{E}_{\theta_{-1}}\left[\left(v-\theta_{1}\right) x_{1}\left(v, \theta_{1}, \theta_{-1}\right)+\sum_{i \neq 1}\left\{v x_{i}\left(v, \theta_{1}, \theta_{-1}\right)-t_{i}\left(v, \theta_{1}, \theta_{-1}\right)\right\}\right] \\
\text { subject to }(I R) \text { and }(I C) .
\end{gathered}
$$

A standard analysis shows that the optimal allocation $x$ solves

$$
\max _{x, t} \mathbb{E}_{\theta_{-1}}\left[\left(v-\theta_{1}\right) x_{1}\left(v, \theta_{1}, \theta_{-1}\right)+\sum_{i \neq 1}\left[v-J_{i}\left(\theta_{i}\right)\right] x_{i}\left(v, \theta_{1}, \theta_{-1}\right)\right]
$$

which coincides with the allocation $x^{*}$ when $v>\hat{v}$. Hence, this delegation scheme implements our optimal mechanism in this case.

REMARK 2 (Equilibrium concept and the form of limited liability). Proposition 3-(ii) specifies a payment rule that compensates the winning firm for the "highest possible cost" that could result in a win given the allocation rule $x^{*}$. This feature, reminiscent of the "pivot" 
mechanism, implements $x^{*}$ in dominant strategies. ${ }^{16}$ In addition, this payment rule satisfies satisfies (LL) in the ex post sense when $v<\hat{v}$, but not when $v>\hat{v}{ }^{17}$ By contrast, the aforementioned delegation mechanism implements the optimal allocation in Bayesian-Nash equilibrium, but not in dominant strategies. Plainly, the innovator's belief about other firms matters for the contracts that it offers. At the same time, the delegation mechanism satisfies the buyer's limited liability constraint ( $L L)$ in the ex post sense. Namely, the buyer is insulated from any ex post loss that she may be exposed to under the dominant-strategy mechanism described in Proposition $3 .^{18}$

\subsection{Comparative Statics and Testable Hypotheses}

Further implications of the optimal mechanism are gained from comparative statics analyses. Due to the complex and rich decisions with respect to ex ante innovation effort and ex post contract assignment, however, general results in this regard are neither easily obtained nor clearly interpretable. Nevertheless, we can perform meaningful comparative statics exercises through a carefully designed thought experiment.

Specifically, we can interpret $\lambda^{*}$ as the buyer's demand for innovation, and see how an increase in $\lambda^{*}$ affects the optimal allocation and the use of a cash prize, holding constant the elicited level of innovation effort. ${ }^{19}$ Even though $\lambda^{*}$ is endogenous, and thus its change reflects changes in primitives in a complicated way, this thought experiment yields useful implications for the ways in which the optimal procurement policy must respond to an increased demand for innovation. Proposition 3 reveals the following:

Corollary 2. As $\lambda^{*}$ increases, (i) the probability of the innovator receiving a follow-on contract decreases for $v<\tilde{v}$ and increases for $v>\tilde{v}$, and $\tilde{v}$ remains unchanged; (ii) $\hat{v}$

\footnotetext{
${ }^{16}$ See Clarke (1971). One difference is that the allocation here is not efficient. We thank a referee for suggesting this payment rule.

${ }^{17}$ To see the former, recall $\rho_{i}(v)=0$ for all $i$ in this case. Fix any such $v$ and any realized profile $\theta=\left(\theta_{1}, \ldots, \theta_{n}\right)$. The buyer's total payment is 0 if no firm is selected. If instead some firm $\ell$ is selected, then

$$
\sum_{i} t_{i}^{*}(v, \theta)=\hat{\theta}_{\ell}\left(v, \theta_{-\ell}\right) \leq v
$$

where the inequality follows from our selection rule, which implies $\hat{\theta}_{\ell}\left(v, \theta_{-\ell}\right) \leq K_{\ell}\left(v, \hat{\theta}_{\ell}\left(v, \theta_{-\ell}\right)\right) \leq v$. When $v>\hat{v}$, the buyer pays the full expected value of the project; hence our dominant strategy mechanism cannot satisfy $(L L)$ in the ex post sense, as budget balancing is incompatible with dominant strategy implementation.

${ }^{18}$ In this sense, our delegation mechanism can be seen as an analogue of the expected externality mechanism (Arrow, 1979; d'Aspremont and Gérard-Varet, 1979) that achieves budget balancing at the expense of dominant strategy implementation.

${ }^{19}$ More precisely, the exercise considers a change in the primitives $\left(F,\left\{G_{i}\right\}, c(\cdot)\right)$ that causes $\lambda^{*}$ to increase and $e^{*}$ to remain unchanged. This thought exercise is not vacuous, as one can easily construct such a change. For instance, if $c(e)$ is linear up to some $\bar{e}>0$ and then becomes vertical, then the buyer wishes to elicit either 0 or $\bar{e}$ for the innovation effort, in which case $e^{*}=\bar{e}$ whenever $\lambda^{*}>0$.
} 
decreases so that the probability of offering a cash prize to the innovator increases.

In words, an increased buyer demand for innovation leads to a more pronounced allocative distortion and a more pronounced use of cash prizes to motivate innovation.

The comparative statics with respect to $\lambda$ provides useful perspectives on how the demand for innovation affects the optimal mechanism. However, the comparative static is not directly testable since $\lambda$ is latent from the analyst's standpoint. Nevertheless, the following testable hypotheses can be obtained from our theory, given an ideal data set that allows one to control for the primitives $\left(F,\left\{G_{i}\right\}, c\right){ }^{20}$

- Hypothesis 1: The innovator is more likely to receive a follow-on contract as the value of innovation $v$ increases. More precisely, fix any environment $\left(F,\left\{G_{i}\right\}, c\right)$ and consider $v<v^{\prime}$. If firm 1 is selected under $v$, then $K_{1}^{*}\left(v, \theta_{1}\right)<\min \left\{v, \min _{j \neq 1} K_{j}^{*}\left(v, \theta_{j}\right)\right\}$. This implies that $K_{1}^{*}\left(v^{\prime}, \theta_{1}\right)<\min \left\{v^{\prime}, \min _{j \neq 1} K_{j}^{*}\left(v^{\prime}, \theta_{j}\right)\right\}$. Hence, firm 1 must also be selected under $v^{\prime}$.

- Hypothesis 2: The innovator is more likely to receive a cash prize as the value of innovation $v$ increases. This follows directly from the fact that, for any fixed environment $\left(F,\left\{G_{i}\right\}, c\right)$, a cash prize is awarded only when the value exceeds a fixed threshold.

- Hypothesis 3: The innovator is more likely to receive a follow-on contract when it also receives a cash prize. This follows from combining the two previous hypotheses. ${ }^{21}$

While testing these hypotheses is beyond the scope of this paper, ${ }^{22}$ features of current practices are consistent with these hypotheses. Consistent with Hypothesis 1, Bhattacharya (2018)'s structural analysis of the US Department of Defense (DoD)'s Small Business Innovation Research (SBIR) program reveals that higher-value innovations are more likely to be converted into follow-on contracts and that they are invariably awarded to the original innovators. Meanwhile, the European Innovation Partnership mentioned above requires the size of a follow-on contract awarded to the innovator to be proportionate to its R\&D investment (Article 31.7 of Directive 2014/24/EU). This is again consistent with Hypothesis

\footnotetext{
${ }^{20}$ One way to obtain this ideal environment is conduct a laboratory experiment, where the experimenter may control the primitives. See, e.g. Camboni et al. (2019).

${ }^{21}$ More precisely, suppose the innovator wins the follow-on contract but does not receive a cash prize. Then, $K_{1}^{*}\left(v, \theta_{1}\right)<\min \left\{v, \min _{j \neq 1} K_{j}^{*}\left(v, \theta_{j}\right)\right\}$ and we must have $v<\hat{v}$. Suppose next that the value $v^{\prime}$ is such that $\rho_{1}\left(v^{\prime}\right)>0$. Then, $v^{\prime}>\hat{v}$, so by Hypothesis 1 , firm 1 must be also selected under $v^{\prime}$.

${ }^{22}$ To test these hypotheses, one may develop a difference-in-difference research design which takes noninnovating firms as a control group and innovation-proposing firms as a treatment group, and test whether the selection of the latter firms for the implementation stage increases with the value of innovations and/or with the awarding of cash prizes. While some of these variables may not be directly observable, the research may use close proxies. For instance, the value of innovation may be proxied by the revenue from the project that embodies the innovation or by innovation expenses, which are often observed.
} 
1 if we take R\&D investment as a proxy of the value of the innovation. Further, in many countries, when the proposer of an unsolicited project does not receive a follow-on contract, it still receives the reimbursement of its development costs up to a cap that is linked to the value of the follow-on contract (e.g., $2.5 \%$ in Italy). ${ }^{23}$ This is consistent with Hypothesis 2 if we interpret the payment as a cash prize and development costs as a proxy for the value of innovation.

\section{Procurement with Multiple Innovators}

We now consider a situation in which multiple firms can propose innovation projects. This situation is relevant when a buyer wishes to procure specific innovative projects, products or services that several firms are capable of developing.

We assume that each firm $k=1, \ldots, n$ can propose a project of value $v^{k}$, which is publicly observable and distributed over $V$ according to a $\operatorname{cdf} F^{k}\left(v^{k} \mid e^{k}\right)$ with density $f^{k}\left(v^{k} \mid e^{k}\right)$, where $e^{k}$ denotes firm $k$ 's innovation effort. ${ }^{24}$ Effort $e$ costs firm $k c^{k}(e)$, which is increasing, strictly convex, twice differentiable and satisfies $c^{k \prime}(0)=0$. Firms make their efforts simultaneously, and we let $\mathbf{e}=\left(e^{1}, \ldots, e^{n}\right)$ denote their efforts and let $\mathbf{v}=\left(v^{1}, \ldots, v^{n}\right)$ denote the values of their innovations. The alternative projects correspond to competing ways of fulfilling the same need, so they are perfect substitutes and the buyer chooses at most one project.

In practice, the cost of implementing a given project may depend on the contractor, but also on the nature of the innovation, including the identity of the innovator. In some cases, the innovator may have cost advantages in implementing the project, for example, because of its superior knowledge of the proposed solution. In other cases, the innovator may have cost disadvantages, for example, because it specializes in R\&D and lacks the manufacturing capabilities necessary to implement the developed prototype. To accommodate such an interdependence between innovation and implementation, we assume that firm $i$ 's cost of implementing project $k$ is given by $\theta_{i}+\psi_{i}^{k}$, where:

- as before, $\theta_{i}$ is an idiosyncratic cost that is privately observed by firm $i$ and distributed according to the cdf $G_{i}$;

- $\psi_{i}^{k}$ is an additional cost, potentially both project- and firm-specific, which for simplicity is supposed to be common knowledge.

\footnotetext{
${ }^{23}$ In practice, the cap is often binding.

${ }^{24}$ Formally, all firms are thus also innovators; the case of a "pure contractor" $k$ can however be accommodated by assuming that $F^{k}$ is concentrated on $\underline{v}$. The previous model can be seen as a special case in which this holds for every $k \neq 1$.
} 
As before, we consider a direct revelation mechanism which, for each $i, k \in N$, now specifies the probability $x_{i}^{k}(\mathbf{v}, \theta)$ that project $k$ is chosen and implemented by firm $i$, as well as the payment $t_{i}(\mathbf{v}, \theta)$ that firm $i$ receives, when project values $\mathbf{v}$ are realized and firms report $\theta$. The buyer seeks to maximize her net surplus subject to the same set of constraints as before: individual rationality, incentive compatibility, limited liability and moral hazard, suitably extended to the current setup. The detailed formulation is relegated to Online Appendix C.

As in the case of a single innovator, we assume that there exists an optimal mechanism that induces interior efforts e. The following Proposition characterizes this optimal mechanism:

Proposition 4. There exists $\lambda^{*}=\left(\lambda^{1 *}, \ldots, \lambda^{n *}\right) \geq 0$ such that the optimal mechanism solving $[P]:$

(i) selects firm $i \in N$ to implement project $k \in N$ (i.e., $x_{i}^{k *}(\mathbf{v}, \theta)=1$ ) if

$$
v^{k}-K_{i}^{*}\left(\mathbf{v}, \theta_{i}\right)-\psi_{i}^{k} \geq \max \left\{0, \max _{(l, j) \neq(k, i)} v^{l}-K_{j}^{*}\left(\mathbf{v}, \theta_{j}\right)-\psi_{j}^{l}\right\}
$$

where

$$
K_{i}^{*}\left(\mathbf{v}, \theta_{i}\right):=J_{i}\left(\theta_{i}\right)-\frac{\beta^{i *}\left(v^{i}\right)}{\left.\max _{2} \max _{k} \beta^{k *}\left(v^{k}\right), 1\right\}} \cdot \frac{G_{i}\left(\theta_{i}\right)}{g_{i}\left(\theta_{i}\right)} \quad \text { and } \quad \beta^{i *}\left(v^{i}\right):=\lambda^{i *} \frac{f_{e}^{i}\left(v^{i} \mid e^{i *}\right)}{f^{i}\left(v^{i} \mid e^{i *}\right)} .
$$

(ii) pays firm $i \in N$ a transfer $t_{i}^{*}(\mathbf{v}, \theta)=\rho_{i}^{*}(\mathbf{v})+\hat{\theta}_{i}^{k}\left(\mathbf{v}, \theta_{-i}\right) x_{i}^{k *}(\mathbf{v}, \theta)$, where

$$
\hat{\theta}_{i}^{k}\left(\mathbf{v}, \theta_{-i}\right):=\sup \left\{\theta_{i} \in \Theta \mid x_{i}^{k *}\left(\mathbf{v}, \theta_{i}, \theta_{-i}\right)=1\right\}
$$

and $\rho_{i}^{*}(\mathbf{v}):=0$ unless $\beta^{i *}\left(v^{i}\right)>\max \left\{\max _{j \in N \backslash\{i\}} \beta^{j}\left(v^{j}\right), 1\right\}$, in which case

$$
\rho_{i}^{*}(\mathbf{v}):=\mathbb{E}_{\theta}\left[\sum_{j, k \in N} x_{j}^{k *}(\mathbf{v}, \theta)\left\{v^{k}-\psi_{j}^{k}-\hat{\theta}_{j}^{k}\left(\mathbf{v}, \theta_{-j}\right)\right\}\right]>0 .
$$

This payment rule implements the allocation rule $x^{*}$ in dominant strategies: that is, it is a weakly dominant strategy for each firm $i$ to report its cost truthfully.

Proof. See Online Appendix C.

Proposition 4 generalizes Proposition 3 in an intuitive way. The allocation of the follow-on contract is distorted for each potential innovator $i \in N$ according to its shadow cost $K_{i}^{*}\left(\mathbf{v}, \theta_{i}\right)$ which "credits" that firm for the incentive benefit $\beta^{i}\left(v^{i}\right)$ its rent contributes when the project 
is worth $v$. As before, there are two cutoffs $\tilde{v}^{i}$ and $\hat{v}^{i}>\tilde{v}^{i}$ such that the innovator is favored in the contract assignment if $v^{i}>\tilde{v}^{i}$ and handicapped if $v^{i}<\tilde{v}^{i}$ and that the innovator receives a cash prize only if $v^{i}>\hat{v}^{i}$. Importantly, this pattern holds for firm $i$ regardless of which project $k$ is chosen.

As before, a cash prize is used when contract rights alone do not provide sufficient incentives, which occurs when a firm $i$ has a project with value $v^{i}$ so high (namely, exceeding $\left.\hat{v}^{i}\right)$ that the incentive benefit $\beta^{* i}\left(v^{i}\right)$ exceeds one. Unlike the single-innovator case, multiple firms may now have such highly valuable projects. Yet, only one firm should receive the prize. The reason for this "winner-takes-all" principle is as follows. Since limited liability binds at the optimum, an additional dollar used for incentivizing an innovator is one less dollar used for incentivizing another innovator. As the incentive benefit is proportional to $\beta^{* i}\left(v^{i}\right)$, the marginal benefit of the prize is maximized by giving the prize to the firm with highest $\beta^{* i}\left(v^{i}\right)$. Consequently, splitting the available cash across firms is never optimal. ${ }^{25}$

The contract assignment is also affected when a cash prize is used. The firm $\hat{\imath}$ with the highest incentive benefit, $\beta^{\hat{\imath} *}\left(v^{\hat{\imath}}\right)$, obtains not only the prize, but also full incentive credit, so its shadow cost reduces again to actual cost: $K_{\hat{\imath}}^{*}\left(\mathbf{v}, \theta_{\hat{\imath}}\right)=\theta_{\hat{\imath}}$. By contrast, every other firm $i \neq \hat{\imath}$ receives a limited credit, proportional to its incentive benefit $\beta\left(v^{i}\right)$ and as a result, its shadow cost remains above the actual cost: $K_{i}^{*}\left(\mathbf{v}, \theta_{i}\right)=\theta_{i}+\left[1-\frac{\beta^{* i}\left(v^{i}\right)}{\beta^{* \hat{\imath}}\left(v^{\hat{\imath}}\right)}\right] \frac{G_{i}\left(\theta_{i}\right)}{g_{i}\left(\theta_{i}\right)}>\theta_{i}$.

An interesting issue arising with multiple innovators is project choice - namely, which project, if any, should be selected. In particular, the nature of interdependence $\left\{\psi_{i}^{k}\right\}_{k, i}$ affects how project choice is tied to contract assignment.

Corollary 3. (i) If $\psi_{i}^{k}=\psi_{i}+\psi^{k}$ for all $i$ and $k$, then a project is chosen independently of $\theta$. Likewise, for any realized $\mathbf{v}$, the follow-on contract is assigned independently of the chosen project. (ii) If $\psi_{k}^{k}-\psi_{k}^{\ell}<\psi_{i}^{k}-\psi_{i}^{\ell}$ for all $k$ and $i, \ell \neq k$, then a project $k$ is more likely to be selected when firm $k$ is selected for implementation than when it is not, and vice versa. (iii) If $\psi_{k}^{k}-\psi_{k}^{\ell}>\psi_{i}^{k}-\psi_{i}^{\ell}$ for all $k$ and $i, \ell \neq k$, then a project $k$ is less likely to be selected when firm $k$ is selected for implementation than when it is not, and vice versa.

ProOF. To prove (i), note that the optimal mechanism selects project $k$ if and only if $v^{k}-K_{i}-\psi^{k}-\psi_{i}>v^{\ell}-K_{i}-\psi^{\ell}-\psi_{i}$, for all $\ell \neq k$, which is equivalent to $v^{k}-\psi^{k}>$ $v^{\ell}-\psi^{\ell}$. Since this does not depend on $\theta$, the statement follows. To prove (ii), suppose project $k$ is chosen when firm $i$ is selected for its implementation. Then, for all $\ell \neq k$, $v^{k}-K_{i}\left(\mathbf{v}, \theta_{i}\right)-\psi_{i}^{k}>v^{\ell}-K_{i}\left(\mathbf{v}, \theta_{i}\right)-\psi_{i}^{\ell}$. Then, since $\psi_{k}^{k}-\psi_{k}^{\ell}<\psi_{i}^{k}-\psi_{i}^{\ell}$,

$$
v^{k}-K_{k}\left(\mathbf{v}, \theta_{k}\right)-\psi_{k}^{k}>v^{\ell}-K_{k}\left(\mathbf{v}, \theta_{k}\right)-\psi_{k}^{\ell}
$$

\footnotetext{
${ }^{25}$ Interestingly, the recipient of a prize need not be the proposer of the highest-value project or of the winning one. For example, if firms can only implement their own projects (i.e., $\psi_{j}^{i}=\infty$ for any $i \neq j$ ) but are otherwise ex ante symmetric (i.e., $\beta^{i *}(\cdot)=\beta^{*}(\cdot)$ ), then the firm with the best project value receives a prize whenever that value exceeds $\hat{v}=\beta^{*-1}(1)$, but its project is not selected if its cost is too high.
} 
That is, if project $k$ is chosen with any firm $i$ as an implementer, project $k$ will also be chosen when firm $k$ is also selected for its implementation. The subsequent statements can be shown analogously.

In case (i), the costs are additively separable, so no firm has a comparative advantage or disadvantage in implementing its own project. In that case, the choices of the project and of the supplier can be separated: a project can be chosen first, before soliciting messages or "bids" from firms; a firm is then selected to implement that project based only on $(\mathbf{v}, \theta)$, regardless of the chosen project. Without additive separability, however, the two choices are intertwined. In case (ii), innovators have a comparative advantage in implementing their own projects, hence the project and supplier choices tend to be bundled. In case (iii), innovators have a comparative disadvantage, and so the project and supplier choices tend to be unbundled.

It is routine to see that the comparative statics established in Corollary 2 carry over to the multiple-innovator case: all else equal, an increase in $\lambda^{i *}$ leads to a greater distortion and an increased use of cash prize for firm $i$. Hypotheses 1 to 3 also generalize to the current context: all else equal, the proposer of a winning project is more likely to be selected for its implementation and/or to receive a cash prize when the project value is high. ${ }^{26}$

REMARK 3. Proposition 4 does not explicitly characterize the set of firms that are induced to innovate. As losing projects are not implemented, innovation efforts are "duplicated". If there is little uncertainty in the outcome of innovation (e.g., if the project values have low variances), then it may be optimal to induce only one firm to exert effort. This is entirely consistent with Proposition 4: $\lambda^{i *}$ will be positive for only one firm $i$ in that case. An asymmetric treatment of firms may thus arise even when firms are ex ante symmetric, as $\lambda^{*}=\left(\lambda^{1 *}, \ldots, \lambda^{n *}\right)$, and thus $\beta=\left(\beta^{1 *}, \ldots, \beta^{n *}\right)$, can be endogenously asymmetric.

In practice, however, multiple firms may be induced to innovate for a couple of reasons. First, if the outcomes of innovation efforts are sufficiently uncertain, then there is a "sampling" benefit from inducing multiple firms to make efforts and generate favorable draws. Second, a buyer, particularly in the public sector, is often prohibited from treating firms differently, especially when they are ex ante symmetric. Proposition 4 remains valid in this case, and we will have $\lambda^{1 *}=\ldots=\lambda^{n *}$. As the highest $\beta^{* i}\left(v^{i}\right)$ then corresponds to the highest $v^{i}$, the highest value project is selected, and only that project can ever be awarded a cash prize.

\footnotetext{
${ }^{26}$ These statements hold even when an innovating firm may have a comparative disadvantage in implementation, as with case (iii) of Corollary 3. Even in this case, innovators are unlikely to be selected for implementing their projects in the absolute sense, but their selection is relatively more likely under the stated conditions.
} 


\section{Extensions}

In this section, we explore several extensions of our baseline model (with one innovator).

\subsection{General welfare function}

Our focus so far has been to maximize the buyer's surplus. In principle, the public procurement authority may act as a social planner who assigns some welfare weight to the firms' profits. We now extend our framework to consider the problem of the planner who maximizes:

$$
W(v, \theta):=\sum_{i \in N}\left[v x_{i}(v, \theta)-t_{i}(v, \theta)\right]+\alpha \sum_{i \in N}\left[t_{i}(v, \theta)-\theta_{i} x_{i}(v, \theta)\right]-\alpha c(e),
$$

where $\alpha \in[0,1]$ is the weight given to firms' profits. The planner faces the same constraints as before, namely, (IR), (IC), (LL), and $(M H)$.

The case $\alpha=0$ corresponds to our baseline model, while $\alpha=1$ corresponds to total surplus maximization. Although the social cost of raising public fund would suggest $\alpha<1$ to be most reasonable, the case of $\alpha=1$ helps clarify the logic behind our main result. One may attribute the favoring of a contract right over a cash prize to the welfare function that regards all rents to the innovator as social costs; contract rents are less costly than cash prizes since they are also needed to support a desired allocation. One may indeed imagine that as $\alpha \rightarrow 1$, the distinction between the two instruments would disappear. However, this is generally not the case. As we show below, our analysis uncovers a new force that justifies the use of contract right as an innovation incentive even when $\alpha \rightarrow 1$. The following proposition characterizes the optimal mechanism:

Proposition 5. The optimal mechanism is characterized same as in Proposition 3, except:

(i) the contract allocation is determined by the shadow costs:

$$
K_{i}^{*}\left(v, \theta_{i}\right):=\left\{\begin{array}{cl}
J_{i}^{\alpha}\left(\theta_{i}\right)-\min \left\{\beta^{*}(v), 1-\alpha\right\} \frac{G_{i}\left(\theta_{i}\right)}{g_{i}\left(\theta_{i}\right)} & \text { if } i=1 \\
J_{i}^{\alpha}\left(\theta_{i}\right)+\max \left\{\alpha \frac{\beta^{*}(v)+\alpha-1}{\beta^{*}(v)+\alpha}, 0\right\} \frac{G_{i}\left(\theta_{i}\right)}{g_{i}\left(\theta_{i}\right)} & \text { if } i \neq 1,
\end{array}\right.
$$

where $J_{i}^{\alpha}\left(\theta_{i}\right):=\theta_{i}+(1-\alpha) \frac{G_{i}\left(\theta_{i}\right)}{g_{i}\left(\theta_{i}\right)}$ is a modified virtual cost, and $\beta^{*}(v):=\lambda^{*} \frac{f_{e}\left(v \mid e^{*}\right)}{f\left(v \mid e^{*}\right)}$.

(ii) the cash prize is awarded to the innovator if and only if $\beta^{*}(v)>1-\alpha$.

(iii) the moral hazard constraint is binding with $\lambda^{*}>0$ either if $\alpha<1$, or if $\alpha=1, n>1$, and $\underline{\theta} \geq \tilde{v}$. 
Proof. See Appendix D.

The characterization resembles that of Proposition 3. Suppose $\lambda^{*}>0$. Then, there are two cutoffs $\tilde{v}<\hat{v}$, given by $\beta^{*}(\tilde{v})=0$ and $\beta^{*}(\tilde{v})=1-\alpha$, respectively, such that the optimal mechanism calls for contract allocation to be distorted against the innovator if $v<\tilde{v}$ and in favor of the innovator if $v>\tilde{v}^{27}$ and for a cash prize to be awarded to the innovator if and only if $v>\hat{v}$. Unlike Proposition 3, however, the moral hazard constraint $(M H)$ need not bind at the optimal mechanism.

Indeed, $\lambda^{*}=0$ if $n=1$ and $\alpha=1$; i.e., there is only one firm and the planner maximizes total surplus. In this special case, the planner attains first best by "selling the project to the innovator," by offering to firm 1 at price equal to $v$ the right to operate the project. In this case, there is no distinction between a contract right and a cash prize; indeed, an optimal policy is to award the contract efficiently and awards the entire surplus to the firm as a cash prize. Indeed, as $\alpha \rightarrow 1, K_{1}\left(v, \theta_{1}\right)$ and $J_{1}^{a}(\theta)$ both tend to $\theta_{1}$ and $\hat{v}$ converges to $\tilde{v}$; in the limit, contract rights play no role in providing incentives for innovation.

However, the same is not true if $n>1$. In that case, the role of contracts rights may not vanish even when $\alpha=1$. Unlike the case of $n=1$, some of the contract surplus must now accrue to non-innovating firms as information rents, and the remaining project surplus may not be sufficient to generate optimal incentive for innovation. ${ }^{28}$ In other words, the moral hazard constraint may be binding with $\lambda^{*}>0$; Proposition 5-(iii) provides a sufficient condition for this. In that case, rents accruing to non-innovating firms become socially costly (despite $\alpha=1$ ) since they limit the amount of cash prize that the planner can award to the innovator to induce optimal innovation. This (endogenous) social cost calls for contract allocation to be distorted in favor of the innovator for $v>\tilde{v}$ and against the firm for $v<\tilde{v}$, just like in our baseline model, but now for a different reason. In this case, even as $\alpha \rightarrow 1$, contract rights remain a significant source of incentives for innovation.

\subsection{Innovation-dependent implementation costs}

In our baseline model, we have assumed that the cost of implementing an innovation project does not depend on its value. We can extend our model to relax that assumption. Specifically, suppose firm $i$ 's cost $\theta_{i}$ of implementing an innovation of value $v$ is distributed according to the cdf $G_{i}\left(\theta_{i}, v\right)$. The dependence of $G_{i}$ on $v$ may be realistic in many contexts. For instance, a higher value project may be more costly to implement. We maintain the assumption that

${ }^{27}$ This conclusion follows from the fact that $K_{1}\left(v, \theta_{1}\right)>J_{1}^{\alpha}\left(\theta_{1}\right)$ and $K_{i}\left(v, \theta_{1}\right)=J_{i}^{\alpha}\left(\theta_{i}\right)$ for $i \neq 1$ if $v<\tilde{v} ; K_{1}\left(v, \theta_{1}\right) \in\left(\theta_{1}, J_{1}^{\alpha}\left(\theta_{1}\right)\right)$ and $K_{i}\left(v, \theta_{1}\right)=J_{i}^{\alpha}\left(\theta_{i}\right)$ for $i \neq 1$ if $v \in(\tilde{v}, \hat{v})$, and $K_{1}\left(v, \theta_{1}\right)=\theta_{1}$ and $K_{i}\left(v, \theta_{1}\right)>J_{i}^{\alpha}\left(\theta_{i}\right)$ for $i \neq 1$ if $v>\hat{v}$.

${ }^{28}$ Even without appropriating full project surplus, the innovator may receive optimal incentives for innovation, if the planner can punish the firm by denying surplus for $v<\tilde{v}$. This punishment ability is curtailed, for example under the sufficient condition of 5 -(iii). 
higher value innovation - even with possibly higher cost required for implementation - is more desirable for the buyer so that the effort incentive constraint is binding at the optimum.

With that assumption, the characterization provided by Proposition 3 carries over, except that firms' shadow costs now depend on $v$. In particular, the incentive benefit for firm 1 is now given by:

$$
\Delta\left(\theta_{1}, v\right):=\beta(v) H_{1}\left(\theta_{1}, v\right)=\beta(v) \frac{G_{1}\left(\theta_{1}, v\right)}{g_{1}\left(\theta_{1}, v\right)} .
$$

As before, this incentive benefit determines the degree to which the contract assignment is distorted relative to the second-best mechanism. Differentiating it with respect to $v$ gives:

$$
\frac{\partial \Delta}{\partial v}(\cdot, v)=\beta^{\prime}(v) H_{1}(\cdot, v)+\beta(v) \frac{\partial H_{1}}{\partial v}(\cdot, v) .
$$

The first term is the one identified by Proposition 3 and still calls for increased assignment of a follow-on contract to the innovator as $v$ increases. The second term, which reflects the impact of $v$ on the informational rents, is new. It reinforces the first term when higher value innovations are more costly to implement and thus likely to entail larger informational rents (i.e., $H_{1}(\cdot, v)$ increases with $v$ ), which we would expect for quality-improving innovations or for technological breakthroughs (examples include vaccines, integrated infrastructures networks, aerospace technologies). ${ }^{29}$ By contrast, when higher value innovations are less costly to implement, they are also likely to generate lower informational rents (i.e., $H_{1}(\cdot, v)$ decreases as $v$ increases); this creates a countervailing effect that mitigates, or even overturns, the positive relationship between the bias and the value of the innovation.

The cost of implementation may not just depend on the value of the innovation project. Rather, an innovator may choose from different types of innovation projects which differ in the costs of implementation. In particular, the innovator may have an incentive to choose an innovation project that it is best positioned to implement. ${ }^{30}$ Such a targeting possibility would further reinforce the main thrust of our results. While the second-best mechanism would actually encourage such self-serving innovation strategies, favoring innovators with high-value projects, as prescribed by our optimal mechanism, would mitigate these incentives and encourage instead the adoption of more valuable innovation strategies.

\footnotetext{
${ }^{29}$ This is in line with the favorable treatment of the innovator in the case of valuable unsolicited proposals, which are often about new products, e.g., new infrastructure projects, rather than about cost-reducing technologies.

${ }^{30}$ In the context of multiple innovators, each innovator may target a project which confers a comparative advantage to the firm, in the sense defined in Corollary 3-(ii).
} 


\subsection{Non-contractible innovation}

So far, we have assumed that the value of innovation, or its proxies, are contractible. In practice, however, it may be difficult for a buyer to commit to a contract contingent on the value of an innovation, as this requires an evaluation procedure that can be reviewed and sanctioned by courts. Furthermore, the optimal mechanism calls for the buyer's surplus to drop discontinuously at $\hat{v}$, as $(L L)$ starts binding. In practice, this feature, an artifact of verifiability of innovation value, is unrealistic. Motivated by these observations, we consider a variant of our baseline model in which the buyer is unable to contract on either the value $v$ of innovation or on any messages on the value from parties who can observe them. ${ }^{31}$ In that case, a feasible mechanism can only depend on messages of $\theta=\left(\theta_{1}, \ldots, \theta_{n}\right)$. Hence, the buyer now commits to a mechanism that depends on firms' ex post cost reports, or "bids," but not on $v$. We further assume that, after observing the realized value $v$ of innovation, the buyer is free to choose whether to implement the project according to the pre-specified mechanism or to cancel the project (if the value is not worth the cost incurred for the implementation). That is, the buyer is unable to commit ex ante to her implementation decision; only her $e x$ post incentive dictates this decision.

Remarkably, our main characterization, except for the use of handicapping, survives this extension:

Proposition 6. In our model with non-contractible innovation, the moral hazard constraint (MH) binds at the optimal mechanism, which also exhibits the following properties:

(i) there exists a cutoff value $\check{v}^{*} \in V$ such that the buyer implements the innovation if and only if $v \geq \check{v}^{*}$;

(ii) in case of implementation, the buyer selects firm $i$ with the lowest shadow cost $K_{i}^{*}\left(\theta_{i}\right)$ to perform that job, where $K_{i}^{*}\left(\theta_{i}\right)=J_{i}\left(\theta_{i}\right)$ for non-innovator $i \neq 1$ and $K_{1}^{*}\left(\theta_{1}\right) \in$ $\left[\theta_{1}, J_{1}\left(\theta_{1}\right)\right)$;

(iii) in case of implementation, the buyer may award a pre-specified level of cash prize;

(iv) if a positive cash prize is awarded, $K_{1}^{*}\left(\theta_{1}\right)=\theta_{1}$;

(v) in case of implementation, the buyer's net surplus is positive and strictly increasing in $v$.

\footnotetext{
${ }^{31}$ Such message-based mechanisms can in theory "fill" the incompleteness of contract, when the values are commonly observed by multiple parties, say the buyer and the innovator in this case (see Maskin and Tirole, 1999). As noted by Aghion et al. (2012), such a mechanism is not very robust to incomplete information. In practice, a contract based on message on the value of innovation is never observed. We thus focus on a model where such message-based mechanisms are not allowed.
} 
Proof. See Online Appendix E.

Similar to the case of contractible innovation, the allocation of the follow-on contract is distorted away from the second-best mechanism. But, as stated in part (ii), the distortion always favors the innovator; namely, it is never handicapped. There is a simple reason for this. Since the innovation is non-contractible now, its assignment cannot depend on the value of innovation: whenever the project is implemented, its follow-on contract must be assigned in the same way, and the same payment rule must apply, regardless of $v$. This means that the only "lever" the buyer has for motivating research effort is her decision to implement the innovation. Even though the buyer cannot ex ante commit to this decision, her ex post incentive can accomplish this goal. She will have an incentive ex post to implement the project only when its value is high enough to justify the payment she must incur, and this means that the innovator earns a rent or a cash prize only when it delivers a sufficiently high-value innovation. The buyer can increase this incentive either by increased contract assignment or by a cash prize. For the same reason as before, at the margin contract rights prove more useful than a cash prize for this purpose. Consequently, the buyer uses contract rights first and awards a cash prize only when contracts rights are already maximally used: no cash prize is given unless the innovator's shadow cost exceeds its actual cost; conversely, when a cash prize is given, as before the buyer can rely on "delegation" to implement the optimal mechanism.

The fact that handicapping is not used against the innovator accords well with its rare use in practice. ${ }^{32}$ Even though the limited use of handicapping may be explained by a variety of reasons such as regulations limiting discriminatory treatment of bidders, the fear of litigation by allegedly mistreated suppliers, or by the concern of possible manipulation, ${ }^{33}$ the proposition suggests that this arises naturally if innovation is non-contractible. Meanwhile, favorable treatment of innovators is more common, and is in line with practices and regulations adopted for unsolicited proposals, such as the Right to Match and Best and Final Offer systems described in Section 5.2.

Finally, part (v) states that the buyer's surplus increases in the value of innovation when it is implemented. This is true even when she pays a cash prize to the innovator. We thus avoid the rather paradoxical result of Proposition 3 that the buyer enjoys no surplus when she

\footnotetext{
${ }^{32}$ While rare in practice, handicapping is not entirely prohibited in public procurement. For instance, article 101 of the EU Procurement Directive 2014/24/EU and Subpart 9.406-2 of the US Federal Acquisition Regulation provide for exclusion of operators whose performance has shown major deficiencies. See also, e.g., Albano, Cesi and Iozzi (2017) on the role for handicaps in the relational contracting literature.

${ }^{33}$ For instance, an innovator with a low-value project may use a proxy to participate in the follow-on tender. In Che, Iossa and Rey (2017), we show how our insights carry over when innovation is contractible but institutional constraints rule out handicaps: the optimal mechanism remains as characterized by Proposition 3 for $v>\tilde{v}$ (where the innovator benefits from a favorable treatment, and with the caveat that banning handicaps may raise the cost $\lambda^{*}$ of the incentive constraint $(M H)$ ), and is otherwise replaced by the standard second-best auction (the handicap is thus replaced by a neutral treatment).
} 
awards a cash prize. In sum, relaxing the contractability of innovations preserves the main thrust of our baseline analysis, while calling into question its less compelling features - such as the use of handicapping and non-monotonic buyer surplus.

\section{$5 \quad$ Policy discussion}

Our results can shed light on innovation procurement policies adopted around the world.

\subsection{Bundling R\&D and implementation}

There are typically two polar approaches in the procurement of innovation: pure bundling and unbundling. With pure bundling, the follow-on contract is awarded to the firm that proposed the innovation concept. Examples include the European Innovation Partnership procedure, for the joint procurement of R\&D services and large-scale production, and US defense procurement in the 1980s, in which the winner of the prototype competition was assured to receive the follow-on contract. ${ }^{34}$ With unbundling, the selection of the project and its implementation are kept separate, the project proposer being treated exactly in the same way as any other firm at the implementation stage. Examples include research contests, the European Pre-commercial Procurement model, and the standard R\&D procurement approach under US federal regulations. ${ }^{35}$

These two approaches can be understood using our characterizations. First, economies (or diseconomies) of scope between R\&D and implementation, as captured by parameters $\left\{\psi_{k}^{\ell}\right\}$, explain the use of pure bundling or unbundling. In keeping with Corollary 3-(ii), if innovators have strong comparative advantages in implementing their own projects, then the optimal mechanism will resemble pure bundling. By contrast, pure unbundling would be optimal when there are diseconomies of scope, as represented by Corollary 3-(iii). This would be the case if firms specialize in either innovation or in implementation (e.g., manufacturing or construction). In this case, the mechanism selects the project from firms specialized in innovation, according to the first-best scheme in Proposition 1 and awards the follow-on contract to a firm specialized in implementation, according to the second-best scheme in Proposition 2.

Second, pure bundling and unbundling may arise even in the absence of economies or diseconomies of scope, if the buyer is unable to commit to partial bundling contingent on the value of innovation, as prescribed by Propositions 3 and 4 . In that case, the decision will

\footnotetext{
${ }^{34}$ On the Innovation Partnerships, see Article 31 of the European Procurement Directive 2014/24/EU; on US defense procurement in the 80s, see Lichtenberg (1988) and Rogerson (1994).

${ }^{35}$ On Pre-commercial procurement, see the Communication from the European Commission $\operatorname{COM}(2007)$ 799 final; on US Procurement regulations see Part 35 of the US Federal Acquisition Regulation.
} 
be made based on the overall strength of the need for providing incentives for innovation. Following Proposition 3, bundling will then be used (only) if the need for incentives is so strong that the benefit from distorting the allocation in favor of the innovator outweighs the cost of allocative inefficiency. From this perspective, procurement of new technologies is more likely to be bundled to the extent that the need for incentives is arguably strong for new technologies. This is in line with real-world practices in public procurement. European legislation limits the use of the Innovation Partnership procedure (which mandates pure bundling) to the procurement of innovative products, services or works unavailable on the market. Further, the law requires, in line with Proposition 6, that the selection of the project be based on both value and cost considerations, and that the size of the follow-on contract reflect the degree of innovation of the proposed solution. ${ }^{36}$

While partial bundling may be difficult to commit to, policy makers often find ways to implement it even when unbundling is formally mandated. A case in point is the SBIR program employed by the DoD, which affirmatively encourages small and medium enterprises (SMEs) to develop innovative projects. Many of these small firms lack large scale production capabilities. Thus, in line with Corollary 3-(iii), there are diseconomies of scope, which would make bundling unattractive. Indeed, the official policy is that the commercialization stage is unbundled from the innovation stage. Nevertheless, the DoD sometimes approaches the winning innovator for a follow-on contract, which the winner can then undertake with external funding or in partnership with a large firm. This form of relational bundling may implement a form of partial bundling envisioned by our theory.

\subsection{Rewarding unsolicited proposals}

Due to the unpredictable nature of innovation, proposals for innovations are often made without any explicit solicitation or request-for-proposal put out by procurement authorities. In around 62 percent of OECD countries, there are legal procedures regulating the submission of such unsolicited proposals by private companies for developing public projects (see Geddes, Germa and Albalate, 2020). These regulations typically require the proposer to submit a technical and feasibility study and the contracting authority to evaluate within a set time frame whether the proposal is sufficiently valuable to be implemented. They often include clauses on how the innovators should be treated in the follow-on tender. The following three arrangements are particularly common (World Bank, 2019):

- Bonus System: The proposer's technical or financial offer receives additional points in the scoring of proposals. Such a system is used, for example, in Chile, Columbia and South Korea.

\footnotetext{
${ }^{36}$ See Recital 49 and Article 31.7 of the European Procurement Directive 2014/24/EU.
} 
- Right to Match System (also known as Swiss Challenge System): The proposer obtains the right to counter-match any better offers. ${ }^{37}$ It is used in India, the Philippines, Peru, Colombia, Jamaica and Italy.

- Best and Final Offer System (also known as Automatic Short Listing): In the context of multi-round tendering, the proposer is guaranteed to participate in the final round. This system is used in Argentina and South Africa.

These mechanisms bias the allocation of follow-on contracts in favor of innovators. ${ }^{38}$

The favorable treatment of the innovator is particularly consistent with Proposition 6, which considers the case of non-contractible innovation. By their very nature, unsolicited innovations are difficult to anticipate, let alone contract on. Hence, a mechanism that rewards an innovator based on the value of innovation - handicapping it for low-value innovations and rewarding it for high-value innovation - as prescribed by Propositions 3 and 4, is difficult to implement. Instead, as prescribed by Proposition 6, the buyer can commit to favor the innovator through pre-specified arrangements such as these systems whenever she chooses to adopt the innovation. Even though the value of innovation may be difficult to verify, such commitment promotes the ex ante incentive for innovation since the buyer will have an ex post incentive to adopt the project - and reward the innovator - if and only if the value of innovation is high enough to justify the cost she must incur. The idea of leveraging the buyer's incentive to incentivize innovation is also found in the bonus system adopted in the South Korea, a country with a long tradition of dealing with unsolicited proposals for infrastructure projects. There, the bidding credit goes up from $5 \%$ to $10 \%$ of the total evaluation score if the contracting authority does not bring any changes to the proposal, which will be the case when the authority finds the proposal to be of particularly high value (World Bank, 2019, pag. 49).

\section{$6 \quad$ Related literature}

Our paper is related to several strands of literature. First, our paper contributes to the literature on procurement. In particular, several authors have argued that a procurer should favor an incumbent contractor on the assignment of follow-on contracts to incentivize his initial R\&D efforts, when these efforts have externalities on other suppliers. This can be achieved

\footnotetext{
${ }^{37}$ See Burguet and Perry (2009) for a formal analysis of the right of first refusal in a procurement context. Their model does not involve ex ante investment, however.

${ }^{38}$ This feature is obvious in the bonus and the best and final offer system. The right to match system also favors the innovators, by allowing them to match any bid exceeding their costs; by contrast, non-innovators will "shade" their bids - namely demand payment that exceeds true costs - and will thus be selected less often.
} 
by single-source contract (i.e, bundling), as shown by Riordan and Sappington (1989) and Bennett and Iossa (2006), or by a bidding-parity bias in the auctioning off of follow-on contracts, as shown by Laffont and Tirole (1988), Bag (1997) and Branco (2002). ${ }^{39}$ While similar in spirit, these papers focus on cost-reducing investments and not value-enhancing investments - the focus of the current paper - , which are arguably more relevant for innovations involving new technologies. As pointed out by Che and Hausch (1999), this distinction matters crucially. Cost-reducing investments are "appropriable" in the sense that they benefit investors directly. Hence, externalities are necessary for rationalizing a biased assignment of follow-on contracts. By contrast, value-enhancing investments are not directly appropriable, so even without externalities these investments are not adequately elicited, making it necessary to use explicit incentives such as contract rights and cash prizes. The mechanism by which these instruments generate incentives is also distinct: the information rents associated with contract rights become key to how these instruments should be combined.

The idea of repurposing future rents as incentives is also featured in the dynamic contracting literature. For example, Board (2011), Andrews and Barron (2016) and Calzolari and Spagnolo (2017) prescribe the "rewarding of good behavior with loyalty" precisely based on the rationale that the rents attached to a future contract can be used as incentives for good behavior. Despite this similarity, these models differ crucially from the current model in two respects. First, they consider the pure moral hazard problem without adverse selection, so rents are not informational as in our model. More importantly, the rich predictions and implications our model generates regarding how the innovator should be favored or disfavored in a procurement context based on the relative costs of alternative firms as well as on the value innovation have no analogues in their model.

Our model is also related to the dynamic adverse selection literature (Pavan, Segal and Toikka, 2014; Garrett and Pavan, 2012), which studies how allocations in multiple periods must be distorted over time to efficiently manage the information rents arising from agents' initial private information. In particular, Garrett and Pavan (2012) use such a model to prescribe a policy in which an incumbent employee is retained more frequently over time. While similar at first glance, the underlying mechanism for their result is quite different from ours. Unlike the current model, in these models the agent does not face limited liability, so any private information the agent observes after the initial contract does not generate information rents for that agent. By contrast, our agents have limited liability, so they earn information rents based on their ex post private information and their use for innovation incentives is what drives the allocation decision in our paper.

\footnotetext{
${ }^{39}$ See also Arozamena and Cantillon (2004) and Piccione and Tan (1996) who study the effect of ex ante investments on the outcome of auctions. Also related is the literature on assigning sequential tasks, which studies the role of information on either the value of the second task (Tamada and Tsai, 2007) or its cost (Hoppe and Schmitz, 2013), and the number of competitors for that task (Li et al., 2015).
} 
Finally, the issue of prizes versus contracts parallels the well-known debate on prizes and patents as alternative methods for motivating innovation efforts (see Maurer and Scotchmer, 2004; Cabral et al., 2006, for reviews). Just like the contract rights in our model, the patent system involves ex post distortions that could be avoided with prizes. The literature on research contests (Taylor, 1995; Fullerton and McAfee, 1999; Che and Gale, 2003; Koh, 2017; Halac, Kartik and Liu, 2017) studies the design of contests for awarding cash prizes. In particular, similar to our Proposition 6, Che and Gale (2003) shows that the buyer's ex post incentive for implementing a high value project can be leveraged to generate incentives for a firm's ex ante non-contractible innovation. However, none of these papers study the follow-on contract phase. Meanwhile, authors have provided rationale for the patent system based on its role of revealing the worth of innovation. For instance, Weyl and Tirole (2012) consider an innovator who has private information about the value of his invention, which can be revealed and properly rewarded by the exercise of her patent right. By contrast, in our model the use of contract rights is rationalized by the reusability of information rents as innovation incentives.

\section{Conclusion}

Procuring innovative projects requires incentivizing research efforts from potential suppliers and implementing the selected projects efficiently. We have shown how the buyer may optimally address these objectives by using contract rights as the primary incentive tool and cash prizes as a supplementary tool. In practice, this can be achieved with bid preference schemes such as those adopted to protect SMEs or to incentivize unsolicited proposals.

A number of issues are worth exploring further. First, we have not explicitly modeled the costs associated with participating in a procurement auction. In practice, submitting a bid often requires significant economic resources (e.g., complex estimations and legal advice), in which case biasing the follow-on tender in favor of the innovator may discourage the participation of potential suppliers. It would therefore be worth endogenizing participation and exploring the implications for the optimal mechanism. ${ }^{40}$

Second, we have focused on a situation where the innovation is valuable to a single buyer and thus has no "market" value. An interesting extension would be to consider multiple buyers and introduce property rights over the commercialization of the innovation. This would allow one to study the balance between innovation incentives and the anti-competitive effects of alternative mechanisms used for the public procurement of innovation.

Third, we have assumed that the buyer is benevolent. In practice, there are concerns

\footnotetext{
${ }^{40}$ For recent work on the role of discrimination in auctions with endogenous entry, see, e.g., Jehiel and Lamy (2015)
} 
about possible corruption involving procurement officers and contractors (see Burguet and Che, 2004). Such a concern may call for limiting the discretion given to the procuring agency. Balancing this with the provision of innovation incentives would constitute another promising research avenue. ${ }^{41}$

\footnotetext{
${ }^{41}$ For recent work on the design of procurement mechanisms in the presence of corruption, see Burguet (2017).
} 


\section{References}

Aghion, Philippe, Drew Fudenberg, Richard Holden, Takashi Kunimoto, and Olivier Tercieux. 2012. "Subgame Perfect Implementation Under Information Perturbations." Quarterly Journal of Economics, 127(4): 1843-1881.

Albano, Gian Luigi, Berardino Cesi, and Alberto Iozzi. 2017. "Public procurement with unverifiable quality: The case for discriminatory competitive procedures." Journal of Public Economics, 145: 14-26.

Andrews, Isaiah, and Daniel Barron. 2016. "The allocation of future business: Dynamic relational contracts with multiple agents." American Economic Review, 106(9): 2742-59.

Arozamena, Leandro, and Estelle Cantillon. 2004. "Investment incentives in procurement auctions." The Review of Economic Studies, 71(1): 1-18.

Arrow, Kenneth. 1979. "The property rights doctrine and demand revelation under incomplete information." In Economics and Human Welfare: Essays in Honor of Tibor Scitovsky, ed. Michael J Boskin, 23-39. New York:Academic Press.

Bag, Parimal Kanti. 1997. "Optimal auction design and R\&D." European Economic Review, 41(9): 1655-1674.

Bennett, John, and Elisabetta Iossa. 2006. "Building and managing facilities for public services." Journal of public economics, 90(10-11): 2143-2160.

Bhattacharya, Vivek. 2018. "An empirical model of R\&D procurement contests: An analysis of the DOD SBIR program." Mimeo, Northwestern University.

Board, Simon. 2011. "Relational contracts and the value of loyalty." American Economic Review, 101(7): 3349-67.

Branco, Fernando. 2002. "Procurement favouritism and technology adoption." European Economic Review, 46(1): 73-91.

Burguet, Roberto. 2017. "Procurement design with corruption." American Economic Journal: Microeconomics, 9(2): 315-41.

Burguet, Roberto, and Martin K Perry. 2009. "Preferred suppliers in auction markets." The RAND Journal of Economics, 40(2): 283-295.

Burguet, Roberto, and Yeon-Koo Che. 2004. "Competitive Procurement with Corruption." The RAND Journal of Economics, 35: 50-68.

Cabral, Luis, Guido Cozzi, Vincenzo Denicolò, Giancarlo Spagnolo, and Matteo Zanza. 2006. "Procuring innovations." In Handbook of Procurement, ed. Nicola Dimitri, Gustavo Piga and Giancarlo Spagnolo, 483-529. Cambridge University Press. 
Calzolari, Giacomo, and Giancarlo Spagnolo. 2017. "Relational Contracts, Procurement Competition, and Supplier Collusion." University of Bologna Discussion Papers.

Camboni, Riccardo, Luca Corazzini, Elisabetta Iossa, and Paola Valbonesi. 2019. "Bid Preferences as Incentives for Innovation: Experimental Evidence." Mimeo.

Che, Yeon-Koo, and Donald B Hausch. 1999. "Cooperative investments and the value of contracting." American Economic Review, 89(1): 125-147.

Che, Yeon-Koo, and Ian Gale. 2003. "Optimal design of research contests." American Economic Review, 93(3): 646-671.

Che, Yeon-Koo, Elisabetta Iossa, and Patrick Rey. 2017. "Prizes versus contracts as incentives for innovation." CEPR Discussion Paper No. DP11904.

Clarke, Edward H. 1971. "Multipart pricing of public goods." Public choice, 17-33.

Clemens, Jeffrey, and Parker Rogers. 2020. "Demand Shocks, Procurement Policies, and the Nature of Medical Innovation: Evidence from Wartime Prosthetic Device Patents." NBER Working Paper No. 26679.

Cozzi, Guido, and Giammario Impullitti. 2010. "Government spending composition, technical change, and wage inequality." Journal of the European Economic Association, 8(6): 1325-1358.

d'Aspremont, Claude, and Louis-André Gérard-Varet. 1979. "Incentives and Incomplete Information." Journal of Public Economics, 11: 25-46.

Decarolis, Francesco, Gaetan de Rassenfosse, Leonardo Giurida, Elisabetta Iossa, Vincenzo Mollisi, Emilio Raitieri, and Giancarlo Spagnolo. 2019. "Buyer Competencies and Innovation Procurement." ZEW Discussion Paper No. 19-057, Mannheim.

EC. 2014. "Quantifying public procurement of R\&D of ICT solutions in Europe, Smart 2011/0036." European Commission.

Edler, Jakob, and Luke Georghiou. 2007. "Public procurement and innovation-Resurrecting the demand side." Research policy, 36(7): 949-963.

Fullerton, Richard L, and R Preston McAfee. 1999. "Auctioning entry into tournaments." Journal of Political Economy, 107(3): 573-605.

Garrett, Daniel F, and Alessandro Pavan. 2012. "Managerial turnover in a changing world." Journal of Political Economy, 120(5): 879-925.

Geddes, Richard, Bel Germa, and Daniel Albalate. 2020. "Do Public-Private Partnership Enabling Laws Increase Private Investment In Infrastructure." Journal of Law and Economics, 63(1): 43-70. 
Geroski, Paul A. 1990. "Procurement policy as a tool of industrial policy." International review of applied economics, 4(2): 182-198.

Halac, Marina, Navin Kartik, and Qingmin Liu. 2017. "Contests for Experimentation." Journal of Political Economy, 125(5): 1523-1569.

Hölmstrom, Bengt. 1979. "Moral hazard and observability." The Bell journal of economics, 10(1): 74-91.

Hoppe, Eva I, and Patrick W Schmitz. 2013. "Public-private partnerships versus traditional procurement: Innovation incentives and information gathering." The RAND Journal of Economics, 44(1): 56-74.

Jehiel, Philippe, and Laurent Lamy. 2015. "On discrimination in auctions with endogenous entry." American Economic Review, 105(8): 2595-2643.

Koh, Youngwoo. 2017. "Incentive and Sampling Effects in Procurement Auctions with Endogenous Number of Bidders." International Journal of Industrial Organization, 52: 393426.

Laffont, Jean-Jacques, and Jean Tirole. 1988. "Repeated auctions of incentive contracts, investment, and bidding parity with an application to takeovers." The RAND Journal of Economics, 19(4): 516-537.

Lichtenberg, Frank R. 1988. "The private R and D investment response to federal design and technical competitions." The American Economic Review, 78(3): 550-559.

Li, Sanxi, Hailin Sun, Jianye Yan, and Jun Yu. 2015. "Bundling decisions in procurement auctions with sequential tasks." Journal of Public Economics, 128: 96-106.

Maskin, Eric, and Jean Tirole. 1999. "Unforeseen contingencies and incomplete contracts." The Review of Economic Studies, 66(1): 83-114.

Maurer, Stephen M, and Suzanne Scotchmer. 2004. "Procuring knowledge." Intellectual property and entrepreneurship: Advances in the study of entrepreneurship, innovation and growth, 15: 1-31.

Myerson, Roger B. 1981. "Optimal auction design." Mathematics of operations research, 6(1): $58-73$.

OECD. 2017. "Government at a-Glance 2017." OECD-Publishing Paris.

OECD. 2019. "Government at a Glance 2019." OECD-Publishing Paris.

Pavan, Alessandro, Ilya Segal, and Juuso Toikka. 2014. "Dynamic Mechanism Design: A Myersonian Approach." Econometrica, 82: 601-653. 
Piccione, Michele, and Guofu Tan. 1996. "Cost-reducing investment, optimal procurement and implementation by auctions." International Economic Review, 37(3): 663-685.

Riordan, Michael H, and David EM Sappington. 1989. "Second sourcing." The RAND Journal of Economics, 20(1): 41-58.

Rogerson, William P. 1994. "Economic incentives and the defense procurement process." Journal of Economic Perspectives, 8(4): 65-90.

Slavtchev, Viktor, and Simon Wiederhold. 2016. "Does the technological content of government demand matter for private R\&D? Evidence from US states." American Economic Journal: Macroeconomics, 8(2): 45-84.

Tamada, Yasunari, and Tsung-Sheng Tsai. 2007. "Optimal organization in a sequential investment problem with the principal's cancellation option." International Journal of Industrial Organization, 25(3): 631-641.

Taylor, Curtis R. 1995. "Digging for Golden Carrots: An Analysis of Research Tournaments." American Economic Review, 85(4): 872-890.

Weyl, E Glen, and Jean Tirole. 2012. "Market power screens willingness-to-pay." The Quarterly Journal of Economics, 127(4): 1971-2003.

World Bank. 2019. "Policy Guidelines for Managing Unsolicited Proposals in Infrastructure Projects, Vol III: Review of Experiences with USPs." The World Bank. 


\section{Appendix}

\section{A Proof of Proposition 1}

To solve $[P-F B]$, we focus on the relaxed problem:

$\left[P^{\prime}-F B\right] \quad \max _{x, t} \mathbb{E}_{v, \theta}\left[v \sum_{i \in N} x_{i}(v, \theta)-t_{i}(v, \theta) \mid e\right]$

subject to $(L L),(M H)$ and

$$
\mathbb{E}_{\theta}\left[t_{i}(v, \theta)-\theta_{i} x_{i}(v, \theta)\right] \geq 0, \quad \forall v, i .
$$

This problem is a relaxation of $[P-F B]$ since $\left(I R^{\prime}\right)$ requires $(I R)$ to hold only on average. At the same time, whenever a mechanism satisfies $\left(I R^{\prime}\right)$, one can construct at least one mechanism that satisfies $(I R)$, without affecting other constraints. Hence, there is no loss in restricting attention to $\left[P^{\prime}-F B\right]$. To solve $\left[P^{\prime}-F B\right]$, we first observe that for each $i \neq 1$, the constraint $\left(I R^{\prime}\right)$ must bind. If not, one can always lower the expected payment to increase the value of the objective without tightening any constraints. Next, define

$$
\rho_{1}(v):=\mathbb{E}_{\theta}\left[t_{1}(v, \theta)-\theta_{1} x_{1}(v, \theta)\right] .
$$

Then, we can weaken $\left[P^{\prime}-F B\right]$ further to:

$\left[P^{\prime \prime}-F B\right]$

$$
\max _{x, t} \mathbb{E}_{v, \theta}\left[\sum_{i \in N}\left(v-\theta_{i}\right) x_{i}(v, \theta)-\rho_{1}(v) \mid e\right]
$$

subject to

$$
\begin{gathered}
\rho_{1}(v) \geq 0, \quad \forall v, \\
\mathbb{E}_{\theta}\left[\sum_{i \in N}\left(v-\theta_{i}\right) x_{i}(v, \theta)\right] \geq \rho_{1}(v), \quad \forall v, \\
\frac{\partial}{\partial e} \mathbb{E}_{v}\left[\rho_{1}(v) \mid e\right] \geq c^{\prime}(e) .
\end{gathered}
$$

Note that the weakening occurs with the moral hazard constraint: $\left(M H^{\prime \prime}\right)$ is a first-order necessary condition of $(M H)$.

Let $\nu(v), \mu(v)$, and $\lambda$ denote the multipliers for constraints $\left(I R^{\prime \prime}\right),\left(L L^{\prime \prime}\right)$ and $\left(M H^{\prime \prime}\right)$, respectively. Then, the Lagrangian (more precisely its integrand) is given by:

$$
L(v, \theta, e):=[1+\mu(v)]\left\{\sum_{i \in N} x_{i}(v, \theta)\left(v-\theta_{i}\right)\right\}-\rho_{1}(v)[1+\mu(v)-\nu(v)-\beta(v)]-\lambda c^{\prime}(e),
$$


where

$$
\beta(v):=\lambda \frac{f_{e}(v \mid e)}{f(v \mid e)}
$$

The optimal solution $\left(e^{F B}, x^{F B}(v, \theta), \rho^{F B}(v), \lambda^{F B}, \mu^{F B}(v), \nu^{F B}(v)\right)$ must satisfy the following necessary conditions.

First, since the Lagrangian is linear in $x_{i}$ 's, the optimal solution $x_{i}^{F B}(v, \theta)$ is as defined in Proposition 1. Next, the Lagrangian $L$ is also linear in $\rho_{1}(v)$; hence, its coefficient must be equal to zero:

$$
1+\mu^{*}(v)-\beta^{*}(v)-\nu^{*}(v)=0
$$

Next, the optimal effort $e^{F B}$ must satisfy

$$
\left.\frac{\partial}{\partial e} \mathbb{E}_{v, \theta}[L(v, \theta, e) \mid e]\right|_{e=e^{F B}}=0 .
$$

Finally, complementary slackness implies that, for each $v$,

$$
\begin{aligned}
& \nu^{F B}(v) \rho^{F B}(v)=0, \\
& \mu^{F B}(v)\left\{\mathbb{E}_{\theta}\left[\sum_{i \in N} x_{i}^{F B}(v, \theta)\left(v-\theta_{i}\right)-\rho_{1}^{F B}(v)\right\}=0,\right.
\end{aligned}
$$

and

$$
\lambda^{F B}\left[\int_{v} \rho^{F B}(v) f_{e}\left(v \mid e^{F B}\right) d v-c^{\prime}\left(e^{F B}\right)\right]=0 .
$$

We first prove that $\lambda^{F B}>0$. Suppose not. Then, $\beta^{F B}(v)=0$ for all $v \in V$. It then follows from (1) that $\nu^{F B}(v)>0$ for all $v \in V$. By (3), this means that $\rho^{F B}(v) \equiv 0$. As $x_{i}=x_{i}^{F B}$, it then follows from (4) that for any $v>\underline{\theta}, \mu^{F B}(v)=0$. Collecting these facts together, we conclude that

$$
\mathbb{E}_{\theta}[L(v, \theta, e)]=\mathbb{E}_{\theta}\left[\max \left\{0, v-\min _{i}\left\{\theta_{i}\right\}\right],\right.
$$

which is increasing in $v$ (and strictly so for a positive measure of $v$ ). By $(M L R P)$, this means that

$$
\frac{\partial}{\partial e} \mathbb{E}_{v, \theta}[L(v, \theta, e) \mid e]>0
$$

a contradiction to (2). We thus conclude that $\lambda^{F B}>0$.

If $v<\hat{v}^{F B}$, then $\beta^{F B}(v)<1$, and thus $1+\mu^{F B}(v)-\beta^{F B}(v)>0$. Hence, by (1), $\nu^{F B}(v)>0$ and, by $(3)$, we have $\rho^{F B}(v)=0$. It in turn follows from (4) that $\mu^{F B}(v)=0$ provided that $v>\underline{\theta}$.

If instead $v>\hat{v}^{F B}$, then $\beta^{F B}(v)>1$, and thus $1-\beta^{F B}(v)-\nu^{F B}(v)<0$. Hence, by (1), 
$\mu^{F B}(v)>0$. But then, by (4), we must have

$$
\rho^{F B}(v)=\mathbb{E}_{\theta}\left[\sum_{i \in N} x_{i}^{F B}(v, \theta)\left(v-\theta_{i}\right)\right],
$$

as claimed in Proposition 1.

Next, we show that $\underline{v}<\hat{v}^{F B}<\bar{v}$. First, by $(M L R P), \beta^{F B}(v)$ is strictly increasing in $v$, and there exists $\tilde{v} \in(\underline{v}, \bar{v})$ such that $\beta^{F B}(\tilde{v})=0(<1)$; it follows that $\hat{v}^{F B}>\tilde{v}(>\underline{v})$. Second, we must have $v>\hat{v}^{F B}$ with positive probability (i.e., $\lambda^{F B}$ cannot be too small). Suppose to the contrary that $\beta^{F B}(v)<1$ for all $v \in V$. Then, as argued above $\rho^{F B}(v)=\mu^{F B}(v)=0$ for all $v \in V$. In this case, by the convexity of $c(\cdot)$, we must have $e^{F B}=0$, or else we obtain a contradiction to (5). But then, we get

$$
L(v, \theta, e)=\max \left\{0, \max _{\theta_{i}}\left(v-\theta_{i}\right)\right\}-c^{\prime}(e) .
$$

As the first term is increasing in $v$ (and strictly so for a positive measure of $v$ ), and $c^{\prime}(0)=0$, we thus get a contradiction to (2).

Finally, we prove that $e^{F B}>0$. Given $\lambda^{F B}>0$, it follows from (5) that

$$
\int_{v} \rho^{F B}(v) f_{e}\left(v \mid e^{F B}\right) d v=c^{\prime}\left(e^{F B}\right)
$$

As $v>\hat{v}^{F B}$ for a positive measure of $v$, the left side is strictly positive. This implies that $e^{F B}>0$, or else the right-hand side vanishes as $c^{\prime}(0)=0$.

\section{B Proof of Proposition 3}

To solve $[P]$, we first reformulate $(I C)$ in terms of interim allocation and payment rules. For each $i \in N$ and for any $v \in V$ and any $\theta_{i} \in \Theta_{i}$, let $X_{i}\left(v, \theta_{i}\right):=\int_{\theta_{-i}} x_{i}(v, \theta) d G_{-i}\left(\theta_{-i}\right)$ and $T_{i}\left(v, \theta_{i}\right):=\int_{\theta_{-i}} t_{i}(v, \theta) d G_{-i}\left(\theta_{-i}\right)$ denote the interim allocation and payment for firm $i$ and

$$
U_{i}\left(v, \theta_{i}\right):=T_{i}\left(v, \theta_{i}\right)-\theta_{i} X_{i}\left(v, \theta_{i}\right)
$$

denote firm $i$ 's expected profit. For each $i \in N,(I C)$ then can be stated as

$$
T_{i}\left(v, \theta_{i}\right)-\theta_{i} X_{i}\left(v, \theta_{i}\right) \geq T_{i}\left(v, \theta_{i}^{\prime}\right)-\theta_{i} X_{i}\left(v, \theta_{i}^{\prime}\right), \forall v, \theta_{i}, \theta_{i}^{\prime} .
$$

The associated envelope condition then yields

$$
U_{i}\left(v, \theta_{i}\right)=\rho_{i}(v)+\int_{\theta_{i}}^{\bar{\theta}} X_{i}(v, s) d s,
$$


where

$$
\rho_{i}(v):=U_{i}(v, \bar{\theta})
$$

is the rent enjoyed by firm $i$ when its cost is highest. Using (7), we can express firm $i$ 's expected rent as

$$
\begin{aligned}
\int_{\theta_{i}} U_{i}\left(v, \theta_{i}\right) d G_{i}\left(\theta_{i}\right) & =\int_{\theta_{i}}\left[\rho_{i}(v)+\int_{\theta_{i}}^{\bar{\theta}} X_{i}(v, s) d s\right] d G_{i}\left(\theta_{i}\right) \\
& =\rho_{i}(v)+\int_{\theta_{i}} X_{i}\left(v, \theta_{i}\right) \frac{G_{i}\left(\theta_{i}\right)}{g_{i}\left(\theta_{i}\right)} d G_{i}\left(\theta_{i}\right) .
\end{aligned}
$$

For each $i \neq 1$, the rent $\rho_{i}(v)$ does not help to relax any constraint and reduces the surplus for the principal, so it is optimal to set $\rho_{i}(v)=0$ for all $v$.

Using (6) and (9), the total expected transfer to the firms can be expressed as:

$$
\begin{aligned}
\int_{\theta} \sum_{i \in N} t_{i}(v, \theta) d G(\theta) & =\sum_{i \in N} \int_{\theta_{i}} T_{i}\left(v, \theta_{i}\right) d G_{i}\left(\theta_{i}\right) \\
& =\sum_{i \in N} \int_{\theta_{i}}\left[U_{i}\left(v, \theta_{i}\right)+\theta_{i} X_{i}\left(v, \theta_{i}\right)\right] d G_{i}\left(\theta_{i}\right) \\
& =\sum_{i \in N}\left\{\rho_{i}(v)+\int_{\theta_{i}} X_{i}\left(v, \theta_{i}\right) J_{i}\left(\theta_{i}\right) d G_{i}\left(\theta_{i}\right)\right\} \\
& =\rho_{1}(v)+\int_{\theta} \sum_{i \in N} x_{i}\left(v, \theta_{i}\right) J_{i}\left(\theta_{i}\right) d G(\theta),
\end{aligned}
$$

where $J_{i}\left(\theta_{i}\right):=\theta_{i}+\frac{G_{i}\left(\theta_{i}\right)}{g_{i}\left(\theta_{i}\right)}$ denotes firm $i$ 's virtual cost.

Using (10), we can rewrite $(L L)$ as follows:

$$
\forall v \in V, \quad \int_{\theta}\left\{\sum_{i \in N} x_{i}(v, \theta)\left[v-J_{i}\left(\theta_{i}\right)\right]\right\} d G(\theta) \geq \rho_{1}(v) .
$$

Let $\mu(v) \geq 0$ denote the multiplier associated with this constraint.

The innovating firm's individual rationality simplifies to

$$
\forall v \in V, \quad \rho_{1}(v) \geq 0 .
$$

Let $\nu(v) \geq 0$ denote the multiplier associated with this constraint.

We next focus on the first-order condition for the effort constraint.

$$
\int_{v} \int_{\theta}\left[\rho_{1}(v)+\frac{G_{1}\left(\theta_{1}\right)}{g_{1}\left(\theta_{1}\right)} x_{1}(v, \theta)\right] d G(\theta) f_{e}(v \mid e) d v \geq c^{\prime}(e) .
$$


Note that we formulate the condition as a weak inequality to ensure the non-negativity of the multiplier. Let $\lambda \geq 0$ be the associated multiplier.

Then, $[P]$ can more succinctly be reformulated as follows:

$$
\begin{gathered}
\max _{e, x(v, \theta), \rho_{1}(v)} \int_{v}\left\{\int_{\theta}\left[\sum_{i \in N} x_{i}(v, \theta)\left[v-J_{i}\left(\theta_{i}\right)\right]\right] d G(\theta)-\rho_{1}(v)\right\} f(v \mid e) d v \\
\text { subject to }(\widehat{L L}),(\widehat{I R}) \text { and }(\widehat{M H})
\end{gathered}
$$

The integrand of the Lagrangian is given by:

$$
\begin{aligned}
L(v, \theta, e):= & {[1+\mu(v)]\left\{\left[v-\theta_{1}-\left(1-\frac{\beta(v)}{1+\mu(v)}\right) \frac{G_{1}\left(\theta_{1}\right)}{g_{1}\left(\theta_{1}\right)}\right] x_{1}(v, \theta)+\sum_{\substack{j \in N \\
j \neq 1}}\left[v-J_{j}\left(\theta_{j}\right)\right] x_{j}(v, \theta)\right\} } \\
& -\rho_{1}(v)[1+\mu(v)-\nu(v)-\beta(v)]-\lambda c^{\prime}(e),
\end{aligned}
$$

where

$$
\beta(v):=\lambda \frac{f_{e}(v \mid e)}{f(v \mid e)} .
$$

The optimal solution $\left(e^{*}, x^{*}(v, \theta), \rho_{1}^{*}(v), \lambda^{*}, \mu^{*}(v), \nu^{*}(v)\right)$ must satisfy the following necessary conditions. First, observe that the Lagrangian $L$ is linear in $\rho_{1}(v)$; hence, its coefficient must be equal to zero:

$$
1+\mu^{*}(v)-\beta^{*}(v)-\nu^{*}(v)=0
$$

where $\beta^{*}(v)=\lambda^{*} \frac{f_{e}\left(v \mid e^{*}\right)}{f\left(v \mid e^{*}\right)}$.

The Lagrangian is also linear in $x_{i}$ 's, so the optimal allocation must satisfy, for every $i, v, \theta$ :

$$
x_{i}^{*}(v, \theta)=\left\{\begin{array}{cc}
1 & \text { if } i \in \arg \min _{j}\left\{\tilde{K}_{j}\left(v, \theta_{j}\right)\right\} \\
0 & \text { otherwise }
\end{array}\right.
$$

where

$$
\tilde{K}_{i}\left(v, \theta_{i}\right):=\left\{\begin{array}{cl}
J_{i}\left(\theta_{i}\right)-\frac{\beta^{*}(v)}{1+\mu^{*}(v)} \frac{G_{i}\left(\theta_{i}\right)}{g_{i}\left(\theta_{i}\right)} & \text { if } i=1 \\
J_{i}\left(\theta_{i}\right) & \text { if } i \neq 1,
\end{array}\right.
$$

Next, the optimal effort $e^{*}$ must satisfy

$$
\frac{\partial}{\partial e} \int_{v} \int_{\theta} L\left(v, \theta, e^{*}\right) f\left(v \mid e^{*}\right) d G(\theta) d v=0 .
$$


Finally, complementary slackness implies that, for each $v$,

$$
\begin{aligned}
& \nu^{*}(v) \rho_{1}^{*}(v)=0 \\
& \mu^{*}(v)\left\{\int_{\theta} \sum_{i \in N} x_{i}^{*}(v, \theta)\left[v-J_{i}\left(\theta_{i}\right)\right] d G(\theta)-\rho_{1}^{*}(v)\right\}=0,
\end{aligned}
$$

and

$$
\lambda^{*}\left[\int_{v} \int_{\theta}\left[\rho_{1}^{*}(v)+\frac{G_{1}\left(\theta_{1}\right)}{g_{1}\left(\theta_{1}\right)} x_{1}^{*}(v, \theta)\right] d G(\theta) f_{e}\left(v \mid e^{*}\right) d v-c^{\prime}\left(e^{*}\right)\right]=0 .
$$

We now provide the characterization. Consider first the case where $v<\underline{\theta}$. From (11), $\tilde{K}_{i}\left(v, \theta_{i}\right) \geq \theta_{i}$, and thus $\tilde{K}_{i}\left(v, \theta_{i}\right)$ and $K_{i}^{*}\left(v, \theta_{i}\right)$ both yield $x_{i}^{*}(v, \theta)=0$ for every $i \in N$; furthermore, $(\widehat{L L})$ and $(\widehat{I R})$ together imply

$$
\rho_{1}^{*}(v)=0=\int_{\theta} \sum_{i \in N} x_{i}^{*}(v, \theta)\left[v-J_{i}\left(\theta_{i}\right)\right] d G(\theta) .
$$

Hence, the characterization of $x_{i}^{*}(v, \theta)$ given in Proposition 3 is correct.

We now focus on the range $v>\underline{\theta}$. Again, there are two cases depending on the value of $v$. Consider first the case $v<\hat{v}$, where $\beta^{*}(v)<1$. Hence, $1+\mu^{*}(v)-\beta^{*}(v)>\mu^{*}(v) \geq 0$, and (11) thus implies $\nu^{*}(v)>0$. The complementary slackness condition (13) then yields $\rho_{1}^{*}(v)=0$. This, together with Lemma C.4 (see Online Appendix C) and the complementary slackness condition (14), implies that $\mu^{*}(v)=0$. Hence, $\tilde{K}_{1}\left(v, \theta_{1}\right)=J_{1}\left(\theta_{1}\right)-\beta^{*}(v) G_{1}\left(\theta_{1}\right) / g_{1}\left(\theta_{1}\right)=$ $K_{1}^{*}\left(v, \theta_{1}\right)$.

Let us now turn to the case $v>\hat{v}$, where $\beta^{*}(v)>1$. Hence, $1-\beta^{*}(v)-\nu^{*}(v)<0$, and (11) thus implies that $\mu^{*}(v)>0$; from the complementary slackness condition (14), we thus have

$$
\rho_{1}^{*}(v)=\int_{\theta} \sum_{i \in N} x_{i}^{*}(v, \theta)\left[v-J_{i}\left(\theta_{i}\right)\right] d G(\theta) .
$$

Suppose $\nu^{*}(v)>0$. Lemma C.4 then implies $\rho_{1}^{*}(v)>0$, contradicting the complementary slackness condition (13). Therefore, $\nu^{*}(v)=0$. It follows now from (11) that $1+\mu^{*}(v)=$ $\beta^{*}(v)$. We therefore conclude that $\tilde{K}_{1}\left(v, \theta_{1}\right)=\theta_{1}=K_{1}^{*}\left(v, \theta_{1}\right)$.

The above characterization is valid only when the optimal allocation is monotonic (another necessary condition from incentive compatibility). This follows the assumption that $\frac{G_{i}\left(\theta_{i}\right)}{g_{i}\left(\theta_{i}\right)}$ is nondecreasing in $\theta_{i}$, which implies that $K_{i}^{*}\left(v, \theta_{i}\right)=J_{i}\left(\theta_{i}\right)$, for $i \neq 1$, and

$$
K_{1}^{*}\left(v, \theta_{1}\right)=J_{1}\left(\theta_{1}\right)-\min \{1, \beta(v)\} \frac{G_{1}\left(\theta_{1}\right)}{g_{1}\left(\theta_{1}\right)}=\theta_{1}+\max \{0,1-\beta(v)\} \frac{G_{1}\left(\theta_{1}\right)}{g_{1}\left(\theta_{1}\right)},
$$

are all nondecreasing in $\theta_{i}$.

We next prove that $\lambda^{*}>0$. Suppose $\lambda^{*}=0$. Then, $\beta^{*}(\cdot)=0$, so (11) again implies that 
$\nu^{*}(\cdot)>0$ and $\mu^{*}(\cdot)=\rho_{1}^{*}(\cdot)=0$. Hence,

$$
L\left(v, \theta, e^{*}\right)=\max \left\{0, v-\min _{i} J_{i}\left(\theta_{i}\right)\right\}
$$

which increases for a positive measure of $v$. It follows that

$$
\left.\frac{\partial}{\partial e} \int_{\underline{v}}^{\bar{v}} \int_{\theta} L(v, \theta, e) d G(\theta) f(v \mid e) d v\right|_{e=e^{*}}=\int_{\underline{v}}^{\bar{v}} \int_{\theta} \max \left\{0, v-\min _{i} J_{i}\left(\theta_{i}\right)\right\} d G(\theta) f_{e}\left(v \mid e^{*}\right) d v>0,
$$

which contradicts (12).

Finally, we show that the expected transfer payment $T_{i}^{*}\left(v, \theta_{i}\right)$ can be implemented with transfers given by

$$
t_{i}^{*}(v, \theta):=\left\{\begin{array}{cl}
\hat{\theta}_{i}\left(v, \theta_{-i}\right)+\rho_{i}^{*}(v) & \text { if } \theta_{i} \leq \hat{\theta}_{i}\left(v, \theta_{-i}\right) \\
\rho_{i}^{*}(v) & \text { otherwise }
\end{array}\right.
$$

where

$$
\hat{\theta}_{i}\left(v, \theta_{-i}\right):=\left\{\begin{array}{cl}
\sup \left\{\theta_{i} \in \Theta \mid x_{i}^{*}\left(v, \theta_{i}, \theta_{-i}\right)=1\right\} & \text { if } x_{i}^{*}\left(v, \theta_{i}, \theta_{-i}\right)=1 \\
\underline{\theta} & \text { otherwise }
\end{array}\right.
$$

From (6) and (7), $T_{i}^{*}\left(v, \theta_{i}\right)$ indeed satisfies:

$$
\begin{aligned}
T_{i}^{*}\left(v, \theta_{i}\right) & =\theta_{i} X_{i}^{*}\left(v, \theta_{i}\right)+\int_{\theta_{i}}^{\bar{\theta}} X_{i}^{*}\left(v, \tilde{\theta}_{i}\right) d \tilde{\theta}_{i}+\rho_{i}^{*}(v) \\
& =\theta_{i} \int_{\theta_{-i}} x_{i}^{*}(v, \theta) d G_{-i}\left(\theta_{-i}\right)+\int_{\theta_{i}}^{\bar{\theta}} \int_{\theta_{-i}} x_{i}^{*}\left(v, \tilde{\theta}_{i}, \theta_{-i}\right) d G_{-i}\left(\theta_{-i}\right) d \tilde{\theta}_{i}+\rho_{i}^{*}(v) \\
& =\int_{\theta_{-i}}\left[\theta_{i} x_{i}^{*}(v, \theta)+\int_{\theta_{i}}^{\bar{\theta}} x_{i}^{*}\left(v, \tilde{\theta}_{i}, \theta_{-i}\right) d \tilde{\theta}_{i}+\rho_{i}^{*}(v)\right] d G_{-i}\left(\theta_{-i}\right) \\
& =\int_{\theta_{-i}} t_{i}^{*}(v, \theta) d G_{-i}\left(\theta_{-i}\right)
\end{aligned}
$$

where the last equality follows from the fact that, as $x_{i}^{*}\left(v, \tilde{\theta}_{i}, \theta_{-i}\right)$ is equal to 1 for $\tilde{\theta}_{i}<$ $\hat{\theta}_{i}\left(v, \theta_{-i}\right)$ and to 0 for $\tilde{\theta}_{i}>\hat{\theta}_{i}\left(v, \theta_{-i}\right)$, we have:

- if $\theta_{i}<\hat{\theta}_{i}\left(v, \theta_{-i}\right)$, then:

$$
\theta_{i} x_{i}^{*}(v, \theta)+\int_{\theta_{i}}^{\bar{\theta}} x_{i}^{*}\left(v, \tilde{\theta}_{i}, \theta_{-i}\right) d \tilde{\theta}_{i}=\theta_{i}+\int_{\theta_{i}}^{\hat{\theta}_{i}\left(v, \theta_{-i}\right)} d \tilde{\theta}_{i}=\hat{\theta}_{i}\left(v, \theta_{-i}\right)
$$


- if instead $\tilde{\theta}_{i}>\hat{\theta}_{i}\left(v, \theta_{-i}\right)$, then:

$$
\theta_{i} x_{i}^{*}(v, \theta)+\int_{\theta_{i}}^{\bar{\theta}} x_{i}^{*}\left(v, \tilde{\theta}_{i}, \theta_{-i}\right) d \tilde{\theta}_{i}=0+\int_{\theta_{i}}^{\bar{\theta}} 0 \times d \tilde{\theta}_{i}=0 .
$$

Hence, the expected payment $T_{i}^{*}\left(v, \theta_{i}\right)$ can be implemented with the transfers $t_{i}^{*}(v, \theta)$. Since the allocation rule is ex post monotonic, meaning $x_{i}^{*}\left(v, \theta_{i}, \theta_{-i}\right)$ is nondecreasing in $\theta_{i}$ for each $\left(v, \theta_{-i}\right)$, the payment rule $t^{*}$ implements the allocation in weakly dominant strategies for each firm $i$. Furthermore, from the above characterization the cash prize $\rho_{i}^{*}(v)$ is zero for a non-innovator (i.e., $\rho_{i}^{*}(v)=0$ for every $i \neq 1$ ) and is also zero for the innovator if $\beta^{*}(v)<1$. To conclude the proof, it suffices to note that, if $\beta^{*}(v)>1$, then from (16) the cash prize $\rho_{1}^{*}(v)$ is equal to:

$$
\begin{aligned}
\rho_{1}^{*}(v) & =\int_{\theta} \sum_{i \in N} x_{i}^{*}(v, \theta)\left[v-J_{i}\left(\theta_{i}\right)\right] d G(\theta) \\
& =\sum_{i \in N}\left\{\int_{\theta_{-i}}\left[\int_{\theta_{i}} x_{i}^{*}\left(v, \theta_{i}, \theta_{-i}\right)\left[v-J_{i}\left(\theta_{i}\right)\right] d G_{i}\left(\theta_{i}\right)\right] d G_{-i}\left(\theta_{-i}\right)\right\} \\
& =\sum_{i \in N}\left\{\int_{\theta_{-i}}\left[\int_{\underline{\theta}}^{\hat{\theta}_{i}\left(v, \theta_{-i}\right)}\left[v-J_{i}\left(\theta_{i}\right)\right] d G_{i}\left(\theta_{i}\right)\right] d G_{-i}\left(\theta_{-i}\right)\right\} \\
& =\sum_{i \in N}\left\{\int_{\theta_{-i}}\left[\int_{\underline{\theta}}^{\hat{\theta}_{i}\left(v, \theta_{-i}\right)}\left[v-\hat{\theta}_{i}\left(v, \theta_{-i}\right)\right] d G_{i}\left(\theta_{i}\right)\right] d G_{-i}\left(\theta_{-i}\right)\right\} \\
& =\int_{\theta} \sum_{i \in N} x_{i}^{*}(v, \theta)\left[v-\hat{\theta}_{i}\left(v, \theta_{-i}\right)\right] d G(\theta),
\end{aligned}
$$

where the third equality follows from the monotonicity of $x_{i}^{*}\left(v, \theta_{i}, \theta_{-i}\right)$ in $\theta_{i}$ and the definition of $\hat{\theta}_{i}\left(v, \theta_{-i}\right)$, whereas the next one uses integration by parts. 